
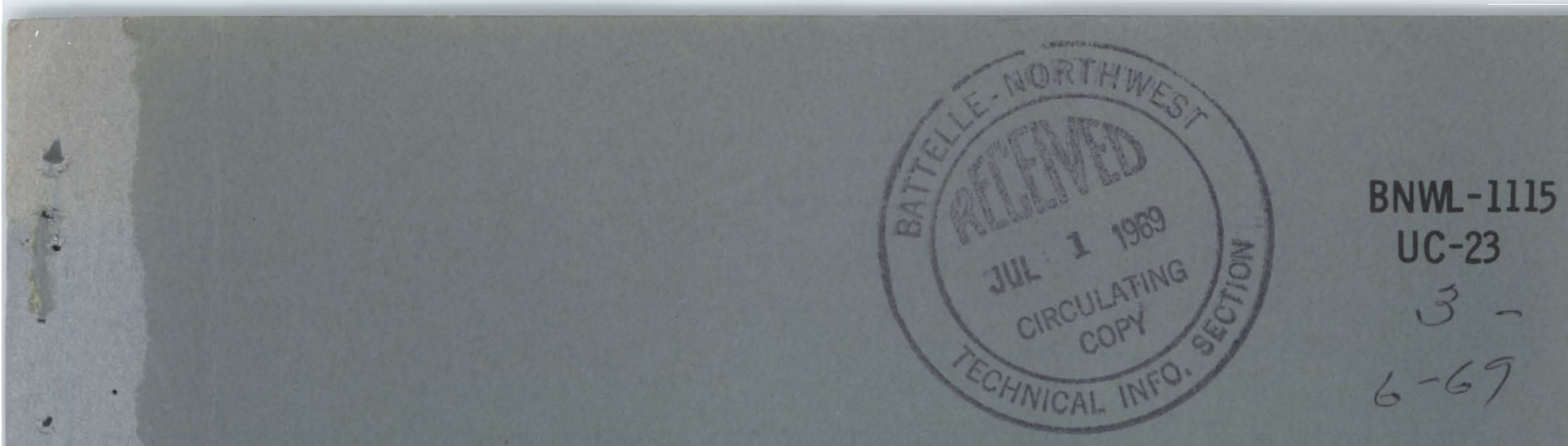

\title{
THE POTENTIAL OF USING MIXED FISSION PRODUCTS AS A SOURCE OF ENERGY
}

June 1969

\section{AEC RESEARCH \& DEVELOPMENT REPORT}

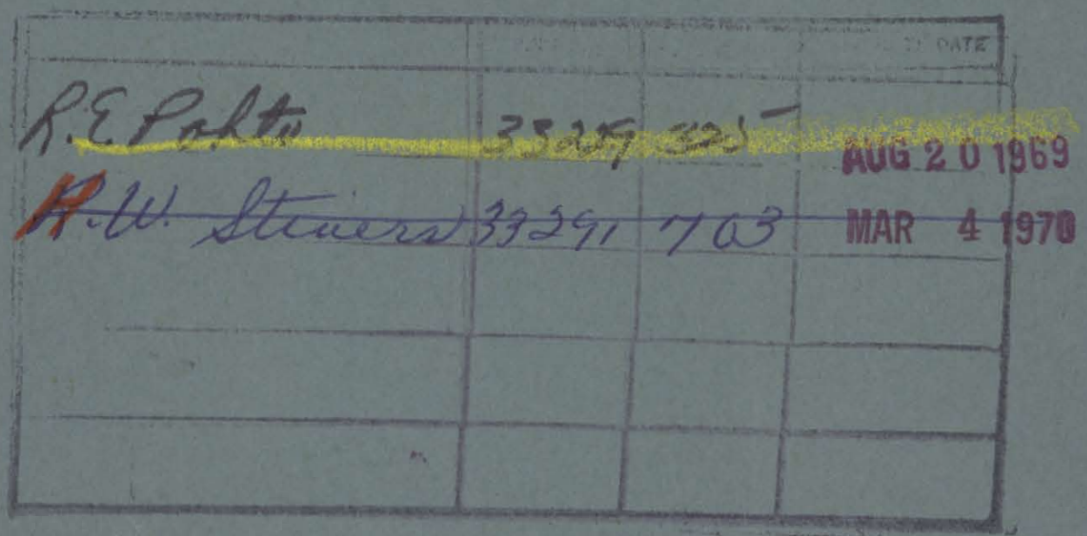




\section{LEGAL NOTICE}

This report was prepared as an account of Government sponsored work. Neither the United States, nor the Commission, nor any person acting on behalf of the Commission:

A. Makes any warranty or representation, expressed or implied, with respect to the accuracy, completeness, or usefulness of the information contained in this report, or that the use of any information, apparatus, method, or process disclosed in this report may not infringe privately owned rights; or

B. Assumes any liabilities with respect to the use of, or for damages resulting from the use of any information, apparatus, method, or process disclosed in this report.

As used in the above, "person acting on behalf of the Commission" includes any employee or contractor of the Commission, or employee of such contractor, to the extent that such employee or contractor of the Commission, or employee of such contractor prepares, disseminates, or provides access to, any information pursuant to his employment or contract with the Commission, or his employment with such contracior.

\section{PACIFIC NORTHWEST LABORATORY}

RICHLAND, WASHINGTON

operated by

BATTELLE MEMORIAL INSTITUTE

for the

UNITED STATES ATOMIC ENERGY COMMISSION UNDER CONTRACT AT(45-1)-1830 
BNWL - 1115

UC-23, Radioisotope and Radiation Applications

THE POTENTIAL OF USING MIXED FISSION PRODUCTS AS A SOURCE OF ENERGY

By

D. W. Bolme

Chemical Technology Department Chemistry and Metallurgy Division

June 1969 
Printed in the United States of America Available from

Clearinghouse for Federal Scientific and Technical Information National Bureau of Standards, U.S. Department of Commerce Springfield, Virginia 22151

Price: Printed Copy $\$ 3.00 ;$ Microfiche $\$ 0.65$ 


\section{THE POTENTIAL OF USING MIXED FISSION PRODUCTS}

\section{AS A SOURCE OF ENERGY}

D. W. Bolme

\section{ABSTRACT}

This study estimates the amount of mixed fission products (waste byproducts obtained in the chemical reprocessing of nuclear fuels) potentially available through the year 2000 , describes their probable characteristics when packaged in a form suitable for long term storage, and assesses the potential usefulness of these packages as sources of thermal and gamma (radiation) energy.

The amounts potentially available depend upon the development of the nuclear (electric) power industry. Initial availability could be as early as 1975, substantial amounts (4800 packages per year) are expected to be available in about 1990 .

Packaging the waste will consist of converting the waste to a solid and depositing the solid in a metal cylinder which would then be welded shut. Typical package dimensions might be those of a 10 inch (diameter) schedule 40 stainless stee 1 pipe $81 / 2$ feet long with a filled height of 8 feet and a total weight of $1000 \mathrm{lb}$.

The characteristics of the mixed fission product cylinders as sources of gamma irradiation are roughly those of a heavily self-shielded source of cesium-134 and 137 which is contaminated with enough cerium-praseodymium-144 to cause shielding problems during transport and handling. Gamma power delivered external to a cylinder containing 2 year old waste will be about 1020 watts including 240 watts from ${ }^{137} \mathrm{Cs}, 585$ watts from ${ }^{134} \mathrm{Cs}, 100$ watts from ${ }^{106} \mathrm{Ru}-\mathrm{Rh}, 37$ watts from ${ }^{144} \mathrm{Ce}-\mathrm{Pr}$ and 58 watts from a11 other nuclides.

Packaged mixed fission products are not expected to be useful in mobile radiators because of the heavy shielding 
made necessary by the ${ }^{144} \mathrm{Ce}-\mathrm{Pr}$. Use of mixed fission products in stationary radiation facilities may be feasible for uses which require a source strength greater than that of 5 megacuries of cobalt and can tolerate large, bulky, diffuse sources.

The packaged mixed fission products (cylinders) are not economically useful sources of thermal energy except, possibly, as a source of process steam for the plant which produces the cylinders. 


\section{CONTENTS}

\section{LIST OF TABLES}

LIST OF FIGURES

SUMMARY AND CONCLUSIONS

INTRODUCTION

Organization

AVA I LAB I L I TY

Nuclear Power Forecas

Mixed Fission Product Forecast

CHARACTERISTICS

Fission Product Distribution

Gamma Spectrum

Comparison of BWR and PWR Wastes

Packaging and Its Effects.

Self-Shielding and Cylinder Wall Shielding.

Fast Flux Reactor Wastes. ECONOMIC EVALUATION

Assumptions

Cask Description

Size and Type of Facility.

Shipping and Handling Cost

Purchase and Maintenance of Source

Mixed Fission Products.

Cesium-137 and Cobalt-60

Discussion

Possible Uses, Irradiation

Possible Uses, Thermal Energy

Value

Plant Size and Cost Limitations

Design Constraints

REFERENCES

APPENDIX A: TABLES

APPENDIX B: FIGURES 


\section{$\underline{T A B L E S}$}

1 Nuclear Power Forecast

2 Availability of (PWR and BWR) Mixed Fission Product Cylinders

3 Amount of Wastes in PWR and BWR Fuels Aged Two Years from Reactor Discharge

$A-2$

A -3

4 Gamma Spectrum of PWR Mixed Fission Products

A -4

6 Major Sources of Gamma Power

A -5

7 Effect of Self-Shielding and Cylinder Wall Sheilding

$A-5$

A -6

8 Power Level of PWR and BWR Cylinders

10 Cost of 70 Kilowatt Gamma Source

\section{FIGURES}

1 Installed Capacity - Nuclear Electrical Generation

2 Gamma Spectra for PWR Mixed Fission Products (2 yr from reactor discharge)

3 Gamma Spectra for PWR Mixed Fission Products (3 yr from reactor discharge)

4 Gamma Spectra for PWR Mixed Fission Products ( 5 yr from reactor discharge)

5 Gamma Spectra for PWR Mixed Fission Products (10 yr from reactor discharge)

6 Gamma Spectra for PWR Mixed Fission Products (20 yr from reactor discharge)

7 Comparison of Gamma Spectra from PWR and BWR Wastes

8 Comparison of Mixed Fission Products and ${ }^{137} \mathrm{Cs}$ Gamma Watts 
THE POTENTIAL OF USING MIXED FISSION PRODUCTS

AS A SOURCE OF ENERGY

D. W. Bolme

SUMMARY AND CONCLUSIONS

This study examines the potential usefulness of mixed fission products as a source of thermal and gamma energy. It is assumed that civilian nuclear fuel reprocessing plants will be solidifying and packaging power reactor wastes because of safety considerations and that use of these wastes (i.e., mixed fission products) as sources of energy would involve only incremental costs.

The conclusions reached in this study are that:

- The amount of solidified mixed fission products potentially available for use will become significant no sooner than about 1975 .

- The packaged mixed fission products (cylinders) are not economically useful sources of heat. Even ignoring capital cost, the cost of handling the cylinders would be more than the heat available is worth. The one possible exception involves recovery of process steam from the shortterm storage facility.

- Packaged mixed fission products are not expected to be useful in mobile radiators because of the heavy shielding made necessary by the ${ }^{144} \mathrm{Ce}-\mathrm{Pr}$.

- Use of mixed fission products in stationary radiation facilities, particularly very large ones, does appear feasible provided the facility can be designed to accommodate these heavy, bulky, sources. Mixed fission products do not start to compete with cobalt-60 until a source equivalent to about 5 megacuries of cobalt is required. 
Summarizing in more detail; if mixed fission products were available for cost of freight, rough1y $\$ 1050$ to obtain one cylinder and $\$ 600$ to dispose of it 18 to 20 years later, and cobalt-60 cost $25 \phi$ per curie delivered, a radiation facility using mixed fission products to provide 70 kilowatts of gamma power (equivalent to 4.8 megacuries of cobalt-60) could justify an additional $\$ 1,340,000$ in capital cost and $\$ 160,000$ in annual operating expense. Extra capital costs made necessary by the use of mixed fission products might typically include a 50 ton crane instead of a 5 ton crane, a $25 \%$ increase in shielding thickness, and a facility large enough to accommodate source wells a foot in diameter instead of a few inches in diameter.

The characteristics of the mixed fission product cylinders as sources of gamma irradiation are roughly those of a heavily self-shielded source of cesium-134 and 137 which is contaminated with enough cerium-praseodymium-144 to cause shielding problems during transport and handling. Gamma power delivered external to a cylinder containing 2 year old waste will be about 1020 watts including 240 watts from ${ }^{137} \mathrm{Cs}, 585$ watts from ${ }^{134} \mathrm{Cs}$, 100 watts from ${ }^{106} \mathrm{Ru}-\mathrm{Rh}, 37$ watts from ${ }^{144} \mathrm{Ce}-\mathrm{Pr}$ and 58 watts from a11 other nuclides.

The amount of mixed fission products potentially available is large. Tentative plans are being developed for solidifying these materials and packaging them in steel cylinders. Potential annual production is 380 cylinders in 1975,1510 in 1980,3070 in 1985, and 4800 in 1990. A typical cylinder might be 10 inches (nomina1) diameter, 8.5 feet tall, and contain the fission products produced by approximately 48,000 megawatt days of fuel exposure.

It will probably be advantageous to hold these cylinders in a short-term cooling facility at the site of production until 
the wastes are 2 years out of the reactor. Use of these cylinders as a source of thermal heat does not appear attractive except, possibly, while they are in this short-term cooling facility. Such a facility, receiving 1000 cylinders per year and storing them $11 / 2$ years, might justify an (additional) capital cost of $\$ 300,000$ to $\$ 500,000$ for the modifications necessary to produce process steam.

Major amounts of fast flux reactor wastes are not expected to become available until 1990 at which time they might account for $20 \%$ of the wastes available. Except for greater amounts of ${ }^{106} \mathrm{Ru}$ the fission product distribution of fast reactor wastes will be roughly the same as BWR or PWR wastes. Because of the extra ruthenium, cylinders containing these wastes might require longer "short-term storage" than cylinders of BWR or PWR wastes but could then be handled in much the same manner.

Cesium separated from power reactor waste is a possible competitor. The sources, if packaged as a part of the waste solidification program might typically be 2 -inch diameter rods 2 feet long containing 60 kilocuries. They would be cheaper to transport and use. The relative economics of mixed fission products versus separated cesium would depend strongly on how the cost of separation was apportioned between the user of the radiation source and the operator of the separations plant (who might separate the $\mathrm{Cs}$ [and $\mathrm{Sr}$ ] in any case in order to make the long term storage of wastes easier).

Separated strontium-90 may also be useful but primarily as a source of heat. Since the mixed fission products are not useful as a source of heat, competition between mixed fission products and strontium-90 does not exist. 


\section{INTRODUCTION}

This report presents information on the amount of mixed fission products which is expected to be available from the nuclear power industry, their characteristics (thermal watts and gamma spectrum as a function of time) and an estimate of the cost of using these materials in car-lot quantities.

The growth predicted for nuclear power in electric generation will result in increased production of (by-product) fission products. These fission products, separated as a waste when the spent fuels are processed to recover uranium, must be prevented from entering the environment. One method of accomplishing this is to convert these materials to a solid form, suitably packaged, ard hold them in very long-term storage. The entire cost of such an operation would have to be bcrne as a cost by some part of the national economy unless profitable use can be found for the fission products.

A substantial amount of work has already gone into investigations of the use of specific isotopes which can be separated from the by-product fission products. This work continues. The separated materials are fairly expensive, however, and the apparent market is not large enough to use all of the radioactive material which will be available. Additional uses, perhaps large scale, may exist if the radioactivity present can be made available in a less expensive form. One possibility is to use the crude mixture of fission products solidified and packaged in the same form as required for long-term (non-use) storage.

This report presents the results of a preliminary study undertaken to estimate 1) the amount of mixed fission products potentially available, 2) the characteristics expected of 
packaged crude fission product mixtures, and 3 ) the (apparent minimum) cost which might be incurred in using these materials in car-lot quantities. A brief discussion of possible methods of using the material is included.

\section{$\underline{\text { ORGAN I ZATION }}$}

This report is, among other things, a summary of a large amount of detailed data. To allow easy perusal of the data, tables and figures are contained on foldout sheets in Appendices $A$ and $B$, respectively.

\section{$\underline{\text { AVA I LAB ILITY }}$}

\section{NUCLEAR POWER FORECAST}

The amount of mixed fission products which will be available is dependent upon the growth in the use of nuclear powered electrical generating plants. The growth expected of this industry has been predicted by a number of people and organizations. One recent, thorough study is that made as part of an isotope production and availability report for the Atomic Energy Commission by McKee, et al. (1968). The growth rate they predicted for the "Most Likely Combination of Liquid Water Reactors Recycling Plutonium and Uranium (U-236) with Introduction of Fast Reactors in 1980" is presented in the first six columns of Table 1 and in Figure 1 . The amount of cesium-137 in the spent fuel discharged from the reactors is presented as a function of time in Column 7 of Table 1 . (These figures are McKee's but differ from his "Annual Availability of Fission Products," because they do not include a $10 \%$ loss in processing, a 2 year delay between "discharge" and "available" and the radioactive decay which would occur during this period.) 


\section{MIXED FISSION PRODUCT FORECAST}

The tonne (metric tons) of spent fuel discharged each year by each type of reactor can be calculated from the data just presented.* This has been done and the results are presented in the last three columns of Table 1 .

As explained later, this study assumes that the wastes from the fuels will be solidified and packaged in cylinders containing, alternatively, the wastes from $11 / 2$ tonne of PWR fue 1 or 2 tonne of BWR fuel, and that these cylinders will be stored until the wastes are 2 years out of the reactor before they are available. Under these conditions, the rate at which cylinders become available will be that presented in Table 2 .

\section{CHARACTERIST ICS}

The characteristics of the mixed fission products potentially available are those of the fission products themselves

* Details of fission product distributions and calculations are presented later. For the purposes of this study, PWR fuels were assumed to have a uniform exposure level of $30,000 \mathrm{MWd} / \mathrm{t}$ and $\mathrm{BWR}$ fuels $25,000 \mathrm{MWd} / \mathrm{t}$. The amount of $137 \mathrm{Cs}$ discharged per megawatt day of exposure was almost identical [PWR was 1.005(BWR)]. If it is assumed that the overall thermal efficiency of the $P W R$ and $B W R$ are the same, and this appears probable, the amount of 137 Cs produced per unit of electricity becomes independent of the type of reactor. Knowing the total $137 \mathrm{Cs}$ produced, the fraction of power produced by each reactor and the amount of $137 \mathrm{Cs}$ per tonne of spent fuel, the tonne (of each type) of fuel to be discharged each year can be calculated. The same approach may be used in predicting fast flux reactor (spent) fuel tonnage. The fraction of fissions which produce ${ }^{137} \mathrm{Cs}$ is slightly higher in a fast reactor (about a $5 \%$ increase) but the power produced per fission is also increased (about $7 \%$ less neutrino production) so the amount of power per unit of $137 \mathrm{Cs}$ wizl remain about the same, about 26,400 MWd per $\mathrm{kg} 137 \mathrm{Cs}$. 
as modified by the matrix in which they are contained, the geometry and shielding characteristics of the package, and age.

\section{FISSION PRODUCT DISTRIBUTION}

The fission product distributions used in this study were predicted by the use of ISOGEN (a computer program originally designed to predict the fission product distributions produced by the Atomic Energy Commission's production reactors) which was modified to use power reactor cross sections [Van Tuy1 (1964)].

This program uses a "chain tracing" technique to calculate the amount of each daughter produced from each of the initial parents. In doing this, the program checks each step and, if the first (Bateman equation) sequence is not suitable, selects one of three algebraic rearrangements of the Bateman equation so as to maintain a numerical accuracy of at least $0.1 \%$ (which is as much as the data normally warrant). Design of the program is such that it can accommodate any actual system of nuclides including branching, neutron capture, fission and feedback at any or al1 nuclides. As used in this study, the program calculated amounts of all nuclides between ${ }^{72} \mathrm{Zr}$ and ${ }^{166}$ Dy having a half life greater than one day, all daughters of such nuclides, and major nuclides between ${ }^{203} \mathrm{TI}$ and ${ }^{250} \mathrm{Cm}$. It can also be used, in a similar fashion, for half lives greater than 1 hour or greater than 10 minutes.

The conditions used in predicting the PWR and BWR fission product distributions are as follows: 
$\frac{\text { Initial Fue 1 }}{235_{\mathrm{U}}}$

$238_{\mathrm{U}}$

Operating "Year"

Operating

Down

Operating

Down

Operating

Down

Number of years

F1ux

$\frac{\text { Number of fissions }}{235 \mathrm{U}}$

$$
239 \mathrm{Pu}
$$

$238_{\mathrm{U}}$

$240+$

Tota 1

Indicated Exposure Power Leve 1

$\frac{\text { PWR }}{33.0 \mathrm{~kg}}$
$967.0 \mathrm{~kg}$

105 days

14 days

105 days

14 days

98 days

28 days

3

$2.2 \times 10^{13}$

$4.655 \times 10^{25}$

$2.104 \times 10^{25}$

$1.399 \times 10^{25}$

$\frac{3.696 \times 10^{22}}{8.161 \times 10^{25}}$

$30,000 \mathrm{MWd} /$ tonne

$32.5 \mathrm{MW} /$ tonne

$\frac{\text { BWR }}{25.6 \mathrm{~kg}}$
$974.4 \mathrm{~kg}$

105 days

14 days

105 days

14 days

98 days

28 days

4

$1.54 \times 10^{13}$

$3.520 \times 10^{25}$

$1.951 \times 10^{25}$

$1.345 \times 10^{25}$

$\frac{2.529 \times 10^{22}}{6.819 \times 10^{25}}$

25,000 MWd/tonne 20.3 MW/tonne

The computer program actually calculated the amount of each of 300 nuclides expected to exist in the fuel. Those nuclides of major importance and their amount in wastes 2 years out of the reactor are presented in Table 3 . These data are based upon a11 nuclides in the discharged fuel less a11 curium, americium, plutonium, and uranium (which would be separated for recycle) and krypton (which would not be included in the solidified waste).

\section{GAMMA SPECTRUM}

The gamma spectrum emitted by the radionuclides obtained from 1 tonne of each of the two fuels is presented as a function 
of time in Tables 4 (PWR) and 5 (BWR). The $\gamma$ power (watts) identified with a particular $\gamma$ energy (MeV) are those associated with the nuclide shown. Those not so identified are a summation of all the $\gamma$ power (watts) contributed at all energy levels falling between the two adjacent designated levels.

In developing Tables 4 and 5 , only major contributors of energy were considered. The individual nuclides were ${ }^{155} \mathrm{Eu}$, ${ }^{154} \mathrm{Eu},{ }^{148 \mathrm{~m}} \mathrm{Pm},{ }^{147} \mathrm{Pm},{ }^{144} \mathrm{Pr},{ }^{144} \mathrm{Ce},{ }^{141} \mathrm{Ce},{ }^{137} \mathrm{Cs},{ }^{134} \mathrm{Cs},{ }^{129} \mathrm{Te}$,

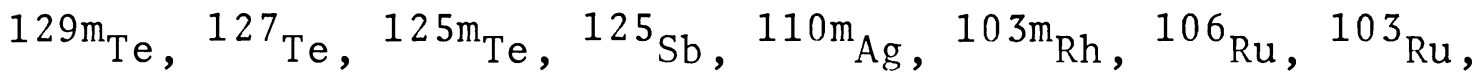

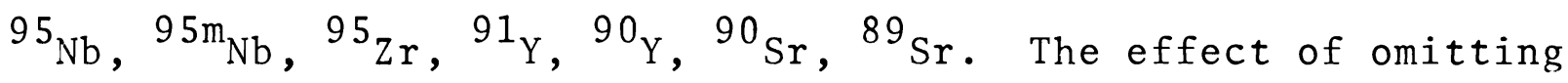
the other nuclides is not important. For example, with PWR fuel at 0.5 years from reactor discharge the nuclides considered accounted for 4620 out of 4623 gamma watts present with the biggest single source of error the exclusion of 1 watt from the La daughter of 12.8 day ${ }^{140} \mathrm{Ba}$.

The gamma spectra for PWR fuels is presented graphically in Figures 2 through 6 at ages of 2, 3, 5, 19 and 20 years. In these figures the solid vertical lines represent the gamma power (watts) released at the specific energy level indicated. The small circles represent the gamma power released between the energy levels which involve major amounts of power.

\section{COMPARISON OF BWR AND PWR WASTES}

The distribution of gamma power from BWR wastes is very similar to that from PWR wastes. Detailed examination of Tables 4 and 5 will indicate this; however, it may be inferred more easily from Table 6 which compares the fraction of total gamma power (watts) contributed by individual nuclides in each case. Less than $5 \%$ of the total gamma power originates in nuclides not common to both materials. 
Alternatively, the power levels of the major peaks emitted by PWR and BWR materials at 2 years from discharge are compared in Figure 7. As may be seen, the two materials are quite similar in gamma ray spectra. This similarity increases with age as the short-1ived materials decay and ${ }^{137} \mathrm{Cs}$ becomes the sole important source of gamma power in both cases.

\section{PACKAGING AND ITS EFFECTS}

The package assumed in this study is a 10 inch (nomina1) diameter schedule 40 stainless steel pipe about 8.5 feet 1 ong with a filled height of 8 feet. Actual dimensions would be 10.75 inch OD; 10.02 inch ID, 0.365 inch wal1 thickness, and the volume of the mixed fission products would be 4.38 cubic feet. The total package weight would be about 1000 pounds. The steel cylinder can routinely be heated during the filling operation to temperatures high enough to cause heat treatment of the steel and produce a surface having a thermal emissivity of about 0.85 . Under normal conditions, the cylinders will be able to discharge all of their internally generated heat by radiation if this is advantageous. Current designs in the Waste Solidification Program require that the external temperature of the cylinder be held below $425^{\circ} \mathrm{C}$ but at this temperature it could radiate heat at a maximum rate of $3630 \mathrm{Btu} / \mathrm{hr}(1.06 \mathrm{~kW})$ per square foot or, neglecting heat loss from ends, 81,700 Btu/hr $(23.9 \mathrm{~kW})$ from the cylinder (less reflection and radiation from the surroundings). This may be compared with the total energy release, of the cylinder, of about $6.6 \mathrm{kw} / \mathrm{cylinder}$ for 2 year wastes.

It has previously been stated that each cylinder would contain the by-product or waste fission products from 1.5 tonne of PWR fuel or 2.0 tonne of BWR fuel or their equivalent. A number of considerations enter into the choice of cylinder 
diameter; filled height, and loading density, the most restrictive of which involves the removal of heat when the cylinder contains 0.5 year waste (i.e., at time of filling). The configuration chosen and described above is obtainable with present technology.

Self-Shielding and Cylinder Wall Shielding

The extent of self-shielding is dependent upon the density and composition of the matrix in which the fission products are contained. Precise calculation of self-shielding is therefore not possible until a particular waste solidification process is chosen for use. A pilot plant investigation of three alternative processes (a phosphate glass process, a pot calcination process, and a spray calcination process) is presently being conducted under the auspices of the Atomic Energy Commission.

An approximation of the self-shielding is reported below in terms of watts delivered at the outside of the package. These calculations are based upon the assumption that the self-shielding characteristics of the solidified mixed fission products will be the same as an equivalent volume of normal concrete with a specific gravity of 2.3. In addition to self-shielding, the effect of the container wall, which will provide shielding equivalent to 0.365 inches of iron, has been included.

Gamma Rays with Initial Energies Less than $0.5 \mathrm{MeV}$ will make little contribution to energies delivered external to the package. The power (watts) contributed by 0.00 to $0.14 \mathrm{MeV}$ gammas are about $1.5 \%$ of the total gamma power released by the mixed fission products and less than onetenth of this will penetrate to the exterior of the cask. The watts contributed by 0.14 to $0.50 \mathrm{MeV}$ gammas are less than $3 / 4 \%$ of the total gamma power emitted and less than 
one-fifth of this is expected to appear as gamma power available at the surface of the cylinder.

Gamma Rays with Initial Energies Between 0.5 and $0.8 \mathrm{MeV}$ contribute about $90 \%$ of the total gamma watts released. The weighted average absorption coefficient for this series of gamma emissions is substantially identical to that of the $0.662 \mathrm{MeV}$ gamma from ${ }^{137} \mathrm{Cs}$. Standard calculations (Rockwe11, Reactor Shielding Design Manual) indicate that the selfshielding expected for $0.66 \mathrm{MeV}$ gamma source, uniformly imbedded in a 10 inch cylinder of concrete, would be the same as that of a line source shielded by 2.5 inches of concrete. Under these conditions, the attenuation of the primary would be 0.3166 in the concrete (self-shielding) and 0.59 in the cylinder wall for a total primary attenuation of 0.187 . The buildup factor (compensation for forward scattering) is more difficult to obtain. It would have to be greater than 1.62 and less than 3.35 with the most probable value between 2.5 and 3.0 . For purposes of this calculation, 2.8 which is what would be predicted for an iron shield producing a primary attenuation of 0.187 ) will be assumed so that total external gamma watts would be $(0.187)(2.8)=0.52$ or $52 \%$ of that released.

Gamma Rays with Initial Energies above $0.8 \mathrm{MeV}$ contribute less than $8 \%$ of the total gamma power released by the mixed fission products. The majority of this is centered about $1.25 \mathrm{MeV}$ and would have a primary attenuation of about 0.3 and a buildup factor of about 2.5. The ${ }^{144} \mathrm{Ce}-\mathrm{Pr}$ gamma at $2.18 \mathrm{MeV}$ would have a primary attenuation of about 0.4 and a buildup factor of about 2.0 . 
Bremsstrahlung will not make a significant contribution to the gamma rays emitted from the packaged wastes. An example may make this obvious. The beta rays from the ${ }^{90} \mathrm{Sr}-\mathrm{Y}$ associated with 1 kilocurie of ${ }^{90} \mathrm{Sr}$ will produce about 1 curie of $0.6 \pm 0.05$ $\mathrm{MeV}$ gamma rays. When first filled with the 2 -year-old wastes from 1.5 tonne of PWR fuel, one cylinder would contain 103.5 kilocuries ${ }^{90} \mathrm{Sr}$ which would emit 103.5 curies of $0.6 \pm 0.05 \mathrm{MeV}$ gamma rays, equivalent to about 0.37 gamma watts which is small compared to the total emission of 1283 gamma watts. Yields are higher at lower energies, but these would be removed by selfshielding and cylinder wall shielding; at higher energies the yields are too low to be important as far as gamma power is concerned. A similar argument holds true for shielding considerations; the amount of $2.0+\mathrm{MeV}$ gammas contributed by ${ }^{90} \mathrm{Sr}-\mathrm{Y}$ bremstrahlung is inconsequential in comparison to the primary gammas of ${ }^{144} \mathrm{Ce}-\mathrm{Pr}$.

The total of these effects would be such that the fraction of the gamma power (watts) released which would be delivered external to the cask would be, roughly, 53\% as shown in Table 7 .

Based upon these estimates the thermal and gamma power delivered exterior to cylinders of PWR and BWR wastes are presented, as a function of time, in Table 8 .

Figure 8 presents a comparison between the gamma power delivered exterior to PWR and BWR cylinders and that from 100,000 curies of cesium-137. It should be noted that the gamma spectrum of the cesium-137 will be almost entirely $0.662 \mathrm{MeV} \gamma$, while almost two-thirds of the energy from the mixed fission products will be the result of buildup and occupy a11 energies between $\sim 0.15 \mathrm{MeV}$ and $0.8 \mathrm{MeV}$. 
One of the problems of mixed fission products is immediately apparent. Even if the material is held in "short term cooling" until 2 years out of the reactor, it still has a high initial decay rate. In the end analysis it is the integrated dose (and therefore the integrated power) which is purchased. The approximate kilowatt hours, both gamma and thermal, which will be delivered each year by one cylinder of PWR waste are presented as a function of time in Table 9 .

In summary, the packaged mixed fission products may be characterized as large sources of ${ }^{134} \mathrm{Cs}$ and ${ }^{137} \mathrm{Cs}$ gamma rays which have 1) self and package shielding sufficient that gamma power delivered is $53 \%$ of that generated and 2) enough ${ }^{144} \mathrm{Ce}-\mathrm{Pr}$ and ${ }^{106} \mathrm{Ru}$ to make shielding for protection during transport etc., a major problem.

\section{FAST FLUX REACTOR WASTES}

The amount of power produced in fast reactors is not expected to become substantial until about 1985. Since there are delays between power production and fuel discharge and between fuel discharge and fuel processing, the wastes from fast reactors are not expected to be important until about 1990 at which time amount of fast reactor wastes would be in approximate proportion to the power production in 1985, roughly, $20 \%$.

The distribution of major fission products in the waste of the fast reactors, particularly after a few years of cooling, is controlled more by the identity of the nuclide fissioned than by the spectrum of the flux. The major difference in the fast reactor waste will arise in the greater importance of plutonium as a source of fission products. The only major radionuclide this affects is ${ }^{106} \mathrm{Ru}$, and a ratio of ${ }^{106} \mathrm{Ru}:{ }^{137} \mathrm{Cs}$ in LMFBR wastes 
will be 3.5 to 4.0 times than in PWR wastes. These wastes would probably be packed at the same "density" (MWd of fission products per cubic feet of waste) as PWR and BWR wastes. They might require longer storage before release for use. After such storage, however, the handling and gamma radiation characteristics of these packaged wastes would be quite similar to those of PWR or BWR wastes.

\section{ECONOMIC EVALUATION}

The economic boundaries within which mixed fission products would have to compete are not well defined. Major potential competitors are cobalt-60 produced by irradiation of the metal or cesium-137 recovered from mixed fission products; however, the price of these materials is not firmly established. Compounding these uncertainties are the questions of type of use, size of source required, and type of facility. This section

(1) characterizes the type and size of applications for which mixed fission products have the best chance of being competitive,

(2) estimates the cost of obtaining and maintaining a mixed fission product source of minimum economic size,

(3) compares this capital and operating cost with those of a similar facility furnishing the same gamma watts by use of cobalt-60 and cesium-137, and

(4) determines the difference in the costs which is, then, the additional capital and operating cost which could be justified for a facility using mixed fission products instead of cobalt or cesium. 


\section{ASSUMPTIONS}

If the nuclear power industry develops as predicted, the production of mixed fission products will exceed present requirements for sources of radiation by orders of magnitude. Since the mixed fission products are a by-product they will be produced whether they are used or not. They will, therefore, be a glut on the market at least in the near term. Any mixed fission products which cannot be used will have to be stored permanently at some cost. Therefore, any use which provides "free" storage of the material would be an improvement over the alternative even if there is no payment for use of the material.

Use of mixed fission products would seem to involve competition with cobalt- 60 produced by private industry. Actually this competition is more apparent than real. Cobalt can be used in facilities of any size including mobile irradiators. The largest existing facilities are in the 100 to 500 kilocurie range while there is at least one (AECL) 1.5 megacurie facility planned and one (RAMCO) facility designed for 5 megacuries under construction. In contrast, it will be shown that mixed fission products cannot be used in mobile irradiators and the smallest potentially economic facility would be in the 1.5 to 5 megacurie range.

Major assumptions, their rationale, and their effect upon the estimated cost are as follows:

(1) It is assumed that solidified mixed fission products, in suitable containers, will be made available to the user at zero cost $F O B$ the short term cooling facility and will be accepted from him at no cost FOB the long term storage facility. 
Rationale - Solidification, packaging, short term cooling, and long term storage of the mixed fission products will be necessary whether they are used or not. Since use of mixed fission products does not impose an added cost in these areas, no costs are included in the cost of using the material. Effect - The user will pay for all extra costs involved in the use of mixed fission products; the source of the mixed fission products will be relieved of the cost of storing the mixed fission products for as long as they are used, and the cost of transporting the MFP from short-term storage facilities (presumably located at the chemical processing plant) to the long term storage facilities.

(2) It is assumed that the mixed fission products will be packaged in one standard package which will be a 10 inch diameter schedule 40 pipe about $81 / 2$ feet tall with a filled height of 8 feet and a total weight of about 1000 pounds.

Rationale - The major problem in packaging these wastes is a combination of heat removal and mechanical strength when they are first filled. The cylinder meets these problems best and appears to be the package which will be used. Effect - No major effect except that the one standard geometry simplifies handling and transport problems.

(3) It is assumed that all shipments of solidified mixed fission products will be made in special casks designed solely for that purpose and that the casks will be in substantially continuous use.

Rationale - The cylinders of solidified mixed fission products will have to be shipped from their point of production to permanent, long-term storage whether they are used enroute or not. The amount expected to 
be shipped (see Table 2) will justify the use of special shipping casks designed to take advantage of the comparatively low cooling requirements and lack of criticality problems which shipment of solidified mixed fission products will involve.

Effect - The cost of shipping mixed fission products to use will be reduced by allowing the use of specially designed casks without imposing penalties because the casks are not completely utilized.

(4) It is assumed that the user of the MFP will pay for use of the cask only while it is used to transport materials to his facility or from his facility to the long term storage sites. Rationale - Same as above. Effect - Little effect except that shared use allows the interest, depreciation, and maintenance on the cask to be charged at a constant rate per trip without having to worry as to whether the industrial use will be large enough to justify a special cask.

(5) It is assumed that the facility using the mixed fission products will be large enough that the amount of mixed fission products required in any one shipment will be equal to all of the material that can be transported by one such cask.

Rationale - The amount of material available will be substantial. Any use large enough to result in important savings (by temporary storage of the mixed fission products) will require major amounts of the material.

Effect - The cost, per unit of material, for loading, transporting, and unloading the mixed fission products will be minimized. 


\section{CASK DESCRIPTION}

The cask used in this estimate is a simple pot and lid assembly capable of containing three cylinders of solidified mixed fission products. Dimensions are:

ID - $\sim 24.5$ inches

OD - $\sim 49.5$ inches

Inside length - $81 / 2$ feet

Outside length - 10 feet 6 inches

Shielding - 11 inches of lead

Weight - 73,000 pounds

Cost @ $\$ 1 / 1 b-\$ 73,000$

Heat generated by the cylinders would be transferred to the inner surface of the cask primarily by radiation, through the cask wall by conduction, and from the cask wall to air by conduction and natural convection. Fins to promote heat transfer from the cask exterior to the air might be advantageous but calculations indicate they are not necessary. The cask would have to be housed during transit to meet personnel protection requirements, both radiation (no approach within 2 feet) and thermal burns from the cask exterior, and the housing would have to be louvered to allow escape of heated air.

\section{SIZE AND TYPE OF FACILITY}

Mobile facilities do not appear to offer much chance for economic use of mixed fission products. The smallest unit of mixed fission products will be one cylinder which, containing wastes 2 years out of the reactor, would supply 1000 watts of gamma power and require a 20 ton cask [to shield against the ${ }^{144} \mathrm{Ce}-\mathrm{Pr}$ (and ${ }^{106} \mathrm{Ru}$ ) gamma rays]. The same gamma power (watts) could be obtained from 310,000 curies of ${ }^{137} \mathrm{Cs}$ or 70,000 curies of ${ }^{60}$ Co with far less weight and volume (both source and cask), 
longer source life, and more flexibility in the design of the facility. Exceptions may occur, of course, i.e., a 20 year old cylinder may prove ideal for some special purpose, but mobile irradiation facilities will not offer an important use for mixed fission products.

Stationary facilities, particularly large, underground stationary facilities, appear to offer the best opportunity for use of mixed fission products. Shielding will remain a problem, of course, but an underground facility can use concrete and earth (instead of lead) and penalties for shielding weight are comparatively minor. Finally, a facility large enough to receive replacement sources in truck load lots (one truckload equals 3 cylinders in one cask weighing about 40 tons loaded) would have an advantage over one which could not. The shipment of one cylinder in a 20 ton cask instead of 3 cylinders in a 40 ton cask would cost at least $50 \%$ more per cylinder. Since shipping cost is the major cost involved in the use of mixed fission products, this is important.

The minimum sized facility capable of accepting 3 cylinder shipments for source maintenance would probably be one requiring 3 cylinders per year. Assuming cylinders were held in use for 18 years this would mean an inventory of 54 cylinders and jump in power (gamma watts) of $20 \%$ when the cylinders were replaced. A more reasonable minimum sized facility would be one requiring four 3-cylinder shipments per year for maintenance of source.

The facility upon which this estimate is based is an irradiation facility furnishing an average gamma power of 70 kilowatts. If this power were furnished by mixed fission products the source inventory would eventually amount to 216 cylinders and require replacement of 12 cylinders per year (assuming that the cylinders would be acquired at age $=2$ years 
from reactor and shipped to permenent storage at age $=20$ years from reactor). An equivalent facility using ${ }^{137} \mathrm{Cs}$ would require an inventory of 24,000,000 curies and addition of 550,000 curies per year for maintenance of source. Use of cobalt-60 would require 5,700,000 curies and 705,000 curies per year.

SHIPPING AND HANDLING COST

The estimated cost of placing the mixed fission products into use is as follows:

Transport

Basis: One truck carrying 1 cask which contains 3 cylinders of mixed fission products. (or one 75 ton railroad car carrying 2 casks) (or one 150 ton railroad car carrying 4 casks) Cost Per Cask of 3 Cylinders Loading (furnished FOB short term cooling facility) \$-0Transport

Shipping and return of empty cask \& $\$ 2.50 /$ cwt. 2000 Cask (capital cost $\$ 73,000$ )

Depreciation a $0.5 \% /$ trip 365

Interest $\& 0.2 \% /$ trip 146 Maintenance \& $\$ 30 /$ trip

Un1oading 350

Transfer ( 3 cylinders) from unloading basin to point of use

Tota1 $\$ 1030 /$ cylinder

Once the cylinders were in place it would be economic to retain them in use for at least 20 years. Eventually, however, the power level would decrease to the point where it would be 
profitable to replace the old cylinders with fresh. The old cylinders would have to be transferred to permanent storage and this cost would be:

Transfer from point of use to unloading basin

$\$ 200$

Load into emptied cask

Transport to final, long term storage* 1000

Cask depreciation, interest, maintenance* 270 Unloading (furnished by long term storage facility)

Tota 1

or $\$ 610 /$ cylinder

\section{PURCHASE AND MAINTENANCE OF SOURCE}

\section{Mixed Fission Products}

Purchase and maintenance of a $70 \mathrm{~kW}$ gamma irradiation facility using mixed fission products would involve:

1. An initial inventory of about 84 cylinders at $\$ 1030 /$ cylinder (enough to provide $70 \mathrm{~kW}$ of gamma energy at the time the first cylinders are added).

2. A periodic addition of 3 cylinders (about 9 cylinders per year) until a total of 216 cylinders was obtained in about 15 years.

3. Replacement of 12 cylinders per year at $\$ 1640 /$ cylinder. Original investment would be:

84 cylinders at $\$ 1030$ per cylinder $\$ 86,520$

Source maintenance would require:

During the 1st 15 years (approximately) Addition of 9 cylinders/year at $\$ 1030 /$ cylinder $\$ 9270 / y r$

Beyond 15 years

The replacement of 12 cylinders/year at $\$ 1640$ per cylinder

* At 50\% of original shipping cost because this shipment would partially replace the return of an empty cask. 
BNWL - 1115

In summary, provision of a source using mixed fission products to produce 70 kilowatts of gamma energy would require an initial capital investment of $\$ 87,000$ and an annual cost not exceeding $\$ 20,000$ per year.

Cesium-137 and Coba1t-60

Provision of the same 70 kilowatts of gamma energy with cesium-137 would require purchase of $24,000,000$ curies initial1y (301 curies per gamma watt and allowing for the first year's decay and for shielding losses of 10\%) and 550,000 curies per year to compensate for annual decay. Cobalt-60 would require 5,700,000 curies plus 705,000 curies per year (same basis except $5 \%$ shielding 10 sses).

The cost of obtaining and maintaining a 70 kilowatt source of gamma energy may therefore be compared as in Table 10. The difference in source purchase and maintenance costs are the extra capital and operating cost which a facility using mixed fission products might justify. As an example, if the competitive source were cobalt-60 at $25 \phi$ per curie, delivered, a facility of this size using mixed fission products could justify an additional capital investment of about $\$ 1,338,000$ and additional operating cost of about $\$ 160,000$ per year.

\section{Discussion}

A look at the difficulties is now in order.

The question of shipping costs for cobalt and cesium has been avoided by specifying delivered costs for cobalt-60 and cesium-137; however, the cask used to ship 3 cylinders (capable of delivering, as mixed fission products, about 3000 watts of gamma power) could, because of lower gamma energies, be used to ship about 40,000 gamma watts of cobalt-60. 
The cask used to transfer individual cylinders of mixed fission products from the unloading basin to the point of use would involve 10 inches of lead, weigh 18 tons and cost $\$ 10,000$, while a cask to transfer the same gamma power in the form of cesium-137 would have a shorter, smaller cavity, require only 8 inches of lead, weigh about 2.5 tons, and cost about $\$ 6,000$.

All handling cranes, etc., would have to be heavier to handle the shielded mixed fission products.

Efficient use of the gamma energy from the mixed fission products would require that the cylinders be spaced enough that most of the radiation would be absorbed before hitting another cylinder. In a water (or similar liquid) system this would require a spacing of about 2 feet between cylinder exteriors which would place the cylinder about 3 feet apart. If a radiation facility were to contain 216 cylinders spaced 3 feet on center, hexagonal, it would occupy about 1800 square feet of area and, assuming an overall height of 12 feet, about 22,000 cubic feet of contained volume.

In contrast, cobalt or cesium sources would not involve 1000 pounds of source for every 325 watts of gamma (average power over 18 years). Gamma absorption by sources would therefore be much less important and the same gamma use efficiency could probably be obtained by a facility one tenth the size-assuming dose rate and hydraulic limitations allowed it.

The shielding thickness required for a mixed fission product is about $25 \%$ greater than that required for a cobalt facility. 
POSSIBLE USES, IRRADIATION

In comparison to pure isotopes, the use of mixed fission products as a source of irradiation presents two problems; the presence of low energy gammas (which must be eliminated if uniformity of dose is important) and the presence of high energy gammas (which increase the cost of shielding and transport but contribute little to total gamma power).

Quantitative calculation of the gamma spectrum delivered external to the cylinder, watts versus $\mathrm{MeV}$, is beyond the scope of this report and is probably not justified until the waste solidification process to be used is determined. As an approximation, $60 \%$ of the gamma watts delivered external to the cylinder will consist of gammas attenuated by the shielding which will be distributed almost uniformly between about $0.15 \mathrm{MeV}$ and the highest major peak $(0.8 \mathrm{MeV}$ in young wastes and $0.66 \mathrm{MeV}$ in wastes over 10 years old). Thirty-two percent will consist of unattenuated primaries at $0.6,0.66$, and 0.8 with an average energy of 0.66 . The remainder, $8 \%$, will consist of high energy primaries and the high energy scatter from them.

Many of the possible uses for irradiation involve systems in which there are penalties for under-exposure or over-exposure or both. The gamma energy requirements vary widely with the individual case, sterilization of packaged bandages is most efficiently done by low energy irradiation (because they are thin in cross section) while preservation of large pieces of meat requires relatively high energy gammas if the center is to be sterilized without over-exposure of the surface. The calculation of individual cases is beyond the scope of this report. 
Those wishing to calculate spectral distributions, dose rates, and integrated dose for individual cases may do so by assuming that, of the gamma watts available at the surface of the cylinder, $60 \%$ are evenly distributed between 0.15 and $0.65 \mathrm{MeV}$; $30 \%$ are at $0.66 \mathrm{MeV}$; and $10 \%$ are at $1.2 \mathrm{MeV}$. More precise calculation may be justified when actual cylinder dimensions, cylinder loading, and matrix compositions are fixed. For the present, however, the approximation suggested will furnish information on dose rate and integrated dose which is as accurate as the data now available.

The limitations in the use of gamma energy with this distribution should be appreciated. The dose rate will be approximately halved after passage through 10 inches of water or equivalent material. Its use to irradiate thick sections would therefore be 1 imited although it might be made almost as good as ${ }^{137} \mathrm{Cs}$ (at some loss in gamma power efficiency) by use of a thin shield of lead or other heavy material with high attenuation for low energy gammas. In any case, it could never compete with coba1t-60 in any use requiring gamma energies greater than $1 \mathrm{MeV}$.

Some speciality uses involving the $2.18 \mathrm{MeV}$ gamma fro
${ }^{144} \mathrm{Ce}-\mathrm{Pr}$ are conceivable but do not seem practical. One cylinder, weighing 1000 pounds, emitting initially 1000 watts of gamma power, and requiring an 18 ton cask, will furnish only 19 watts of $2.18 \mathrm{MeV}$ gamma and it would be cheaper to obtain this amount of high energy gamma power by the use of a pure source.

Systems which can be we11 mixed or which can accept underor over-exposure without major penalties can be handled more easily. Examples might include promotion of chemical reactions and irradiation of sewage. The approximate kilowatt hours 
delivered each year by one cylinder of PWR waste have already been presented as a function of time in Table 9.

Knowing the gamma power emitted from the cylinder, one may calculate the irradiation which one cylinder can furnish. One $\mathrm{kW}$-hr equals $36 \times 10^{12}$ ergs and one rad (water) equals 100 ergs/gram or 378,540 ergs/gallon. A cylinder of 2 year waste could, therefore, expose a maximum of 1900 gallons per hour at $5 \times 10^{4} \mathrm{rad}$ or 380 gallons per hour at $2.5 \times 10^{5} \mathrm{rad}$.

In an actual installation the cylinders would vary in age. The facility used as a basis of cost comparison, containing 216 cylinders varying in age from 2 to 20 years, would supply 70 kilowatts of gamma energy. If this were utilized at $75 \%$ efficiency to irradiate water, it could process 100,000 gallons per hour at $5 \times 10^{4} \mathrm{rad}$ or 20,000 gallons per hour at $2.5 \times 10^{5}$ rad.

Such a facility could be used for commercial production of chemicals by process which include a chemical reaction requiring initiation by gamma irradiation. The annual production would depend upon the $G$ value of the reaction (molecules produced per 100 electron volts absorbed). If $80 \%$ of the gamma watts delivered at the exterior of the cylinder were used to promote a reaction with a $G$ value of 100 in a plant operating $90 \%$ of the year, the facility would produce 36,000 pound moles of product per year.

One potential use of irradiation which would require huge amounts of gamma power might be the use of radiation to sterilize the sewage from a major metropolitan area. This approach is being actively investigated and preliminary estimates of the dose necessary to kill bacteria and viruses have been made. See, for example, Touhill et a1. (1968). 
Some knowledge of its effect on noxious chemicals, and the biodegradability of the effluent stream is also available. An integrated dose of $2.5 \times 10^{5}$ rad appears to be necessary for a good kill of the microorganisms. Supplying this much radiation in a large, metropolitan sewage treatment plant, which might typically treat $1 \times 10^{9}$ gallons per day, would require $110,000 \mathrm{~kW}$ of gamma energy applied to the liquid. Supplying this amount of energy from mixed fission products is not practical. Even if one ignores the problems of initial inventory the maintenance of source would require 20,000 to 25,000 cylinders per year - roughly four times the production forseen for the year 2000. Such a facility based upon mixed fission products or on fission product cesium is therefore out of the question for at least 50 years.

A similar irradiation facility based upon cobalt-60 is at least theoretically possible. At $25 \phi$ per curie for cobalt-60 such a facility would cost $\$ 2,000,000,000$ for source and $\$ 250,000,000$ per year for source maintenance.

\section{POSSIBLE USES, THERMAL ENERGY}

Present uses of radioactive material as a source of thermal power are limited to applications which require a small amount of power in relatively inaccessible locations. The needs of this market are met by the use of relatively pure isotopes which are chosen to provide the optimum balance between cost, power, power density, and weight including the weight of the necessary shielding. Most of the isotopes used require relatively little shielding. In competing for this market, mixed fission products would have to bear the cost and inconvenience of the heavy shielding these materials require. While it is conceivable that mixed fission products could be used for some of these applications, the amount required would be small in comparison to the amount 
available. As a result, expansion of present thermal uses is not expected to provide an important market for mixed fission products.

The best potential opportunity for the use of a major amount of mixed fission products as a source of thermal energy would appear to involve a large facility handling a substantial amount of material. Since the gamma spectrum of the material makes shielding, transport, and handling a major cost, this should be minimized as should the capital required.

It has previously been assumed that the solidified mixed fission products would require storage (to allow for decay of short-lived nuclides) for 1 or 2 years prior to industrial use or transport to permanent storage. If this is true, the most economical method of producing thermal power from the MFP would be to use the short-term storage facility as a source of heat. In doing this, both the rate of heat production and the amount of heat produced per unit of MFP would be maximized because the energy of the short-lived nuclides would be used. At the same time, capital cost would be minimized and handling cost would be eliminated. Whether the heat is used or not, any short-term storage cooling facility will have to shield and cool the MFP containers and the containers will have to be placed in the facility and later removed. Capital cost for a heat producing facility (over and above that required for a heat wasting shortterm storage facility) would include the extra cost required by the distortion of the storage facility necessary to produce usable heat and the cost of any equipment required to use the heat. Extra handling, surveillance, and transportation costs would be minimal or nonexistent. 
$\underline{\text { Value }}$

The total energy liberated by one cylinder of mixed fission products while aging from 0.5 to 2.0 years is equivalent to about $408 \times 10^{6}$ Btu. Substantially all of this will be converted to heat while the cylinder is in the short-term storage facility and its value is the value of the fossil fuel necessary to furnish the same amount of heat. Prices for fossil fuel vary with location and size of user but recent prices for large amounts of fossil fuel, delivered, have ranged from $17 \&$ to $34 \phi$ per million Btu [Hoyerton (1968)] with $25 \phi$ as a national average [Shaw $q$ Whitman (1968)]. Thermal efficiencies in the short-term storage facility would probably be less than the $80 \%$ obtained in commercial package boilers. Assuming $25 \$$ per million Btu for fossil fuel and a $67 \%$ thermal efficiency in the short-term storage facility, the heat released by one cylinder would be the same as that obtained from about $\$ 100$ worth of fossil fuel.

Plant Size and Cost Limitations

If one assumes a waste solidification plant which produces 1000 cylinders of mixed fission products per year (processing the wastes from 1000 tonne of BWR and 750 tonne of PWR fue 1 per year), the heat produced by the short-term storage facility would be equivalent to about 36,500 pounds of steam per hour. A package boiler to produce this much steam would cost about $\$ 90,000$ and require $\$ 100,000$ worth of fuel per year. If heat from the short-terni storage facility is to be competitive, the (extra) capital required by the distortion of the facility to produce usable heat should not exceed $\$ 90,000$ except as it can be justified by the "free fuel" worth $\$ 100,000$ per year. If such an expenditure requires a 2 year write-off to be justified, the total extra capital required to produce usable heat should not 
exceed $\$ 290,000$. These figures might be increased for a small scale user. If the competitive fuels were coal at $\$ 25$ per ton or natural gas at $5 \notin$ per Therm. $(100,00 \mathrm{C}$ Btu), the allowable cost might be doubled.

A11 of this assumes that there is a need for the heat at the site but this appears probable. If nothing else, steam will be required by both the chemical processing plant and the waste solidification facility.

\section{$\underline{\text { Design Constraints }}$}

The primary functions of the short-term cooling facility will be to cool the cylinders of solidified waste enough to prevent damage from their own internally generated heat, provide distance and shielding enough to protect the surroundings from ganma radiation, and contain any fission products which might escape from an imperfect cylinder. Since the cylinders will have to be placed in and removed from the facility on a regular basis, it will probably be compartmentalized and have a number of loading ports. These ports, and the probability of their leaking will mean that the cylinders themselves will. probably be stored at slightly less than atmospheric pressure.

If the heat produced in the short-term cooling facility is to be wasted, the cylinders will probably be cooled by being immersed in water boiling at or slightly below atmospheric pressure. The steam produced would be condensed for recycle, by an air or water cooled condenser.

If the facility is designed to produce saturated steam at or above atmospheric pressure, it would probably be necessary to remove the heat by transferring it from the cylinders to a high temperature fluid. The best material would probably be 
water circulated in pipes under pressure although liquid metals or proprietary heat transfer materials might be used. Since the cylinders can be allowed a high surface temperature $\left(425^{\circ} \mathrm{C}\right)$ and have a high emissivity $(0.85)$ it might be possible to design a facility which would allow transfer of all of the heat to the cooling coils by radiation. The distortion of the facility necessary to produce useful heat in this case would be the replacement of an immersion facility and condenser with a facility cooled by coils. This could have advantages. The facility would operate hot and dry and corrosion problems might be avoided. Contamination from an imperfect cylinder would not be distributed or carried by the cooling media.

An alternative approach might be to cool the cylinders with water boiling near atmospheric pressure, condense this for recycle by boiling water at still lower pressure, and raise the pressure of the secondary steam with a turbo compressor. This has never proven attractive in the United States; however, industrial installations do exist (e.g., in Norway where fuel is expensive and electric power is cheap).

Production of superheated steam could probably be handled in the same sort of high pressure coil system already discussed as a method of producing high pressure saturated steam. A detailed assessment of these possibilities is beyond the scope of this report, the amount of electric power which could be obtained would depend upon the pressure of the superheated steam and this would, in turn, depend on the design of the facility and the pressure drop in the coils.

An alternative to high pressure cooling coils might involve production of sub-atmospheric pressure superheated steam (e.g., 14 psia and $500^{\circ} \mathrm{F}$ ) with direct contact between the steam and the cylinders. Use of this steam would require a low pressure 
steam turbine capable of remote operation (because the steam might be contaminated by a leaking cylinder). This could involve major design problems in the short-term cooling facility and in the turbine. If a facility were receiving 1000 cylinders per year and recovering $67 \%$ of the energy as heat, the electrical production would not exceed $1200 \mathrm{~kW}$ if the steam were produced at $14 \mathrm{psia}$ and $500^{\circ} \mathrm{F}$ or $2400 \mathrm{~kW}$ if produced at $100 \mathrm{psia}$ and $800^{\circ} \mathrm{F}$.

In any case, if the heat is to be removed from the MFP containers by steam or air, the cooling fluid should enter the facility near the youngest wastes, which need the most cooling, and travel towards the oldest wastes. This is similar to "co-current" operation but it does not imply the poor efficiency normally associated with co-current heat exchangers. In contrast to the normal heat transfer problem, the rate at which heat is transferred from the heat source (the mixed fission products) is not determined by the temperature difference between the source and its surroundings. The reverse is the case. The heat is generated at a predetermined rate in each cylinder and the temperature of the cylinder adjusts itself to transfer the necessary heat to its surroundings.

Extraction of thermal energy other than in the short-term storage facility is technically possible, of course, but economics eliminate it. If all the energy liberated by one cylinder of mixed fission products were converted to thermal heat, the amount liberated between ages 0.5 years and 20.0 years (from reactor discharge). Would be less than $1400 \times 10^{6}$ Btu $\left(1126 \times 10^{6}\right.$ Btu leaving the cylinder as heat plus $72,700 \mathrm{~kW}-\mathrm{hr}$ leaving the cylinder as gamma energy which could be converted to an additional $248 \times 10^{6}$ Btu of heat). It would cost $\$ 1030$ to obtain 
this cylinder and $\$ 610$ to dispose of it. Total cost $=\$ 1640$ per $1400 \times 10^{6} \mathrm{Btu}$. The same amount of heat delivered as fossil fuel would cost an industrial user less than $\$ 1000$, and the heat would be available immediately instead of being delivered over 18 years. The use of mixed fission products as sources of thermal energy (heat) is therefore eliminated by economics without even considering the (additional) capital cost required for the heat recovery facility. The writer can see no circumstances which could change this situation in the forseeable future. 


\section{REFERENCES}

J. F. Hoyerton. Scientific American, vol. 218, no. 2. 1968.

R. W. McKee, D. E. Deonigi and D. R. Haffner. Isotope Production Projections for U.S. Nuclear Power Reactors, BNWL-SA-1529. Presented at the American Chem. Soc. Meeting, San Francisco, Calif., April 1968; also, Isotope Production and Availability from Power Reactors, BNWL-716, BattelleNorthwest, Richland, Washington. July 1968.

M. Shaw and M. Whitman. Science and Technology, vol. 22. March 1968.

C. J. Touhill, E. C. Martin, M. P. Fujihara, D. E. Olesm, J. E. Stein and G. MeDonnell. The Effects of Radiation on Chicago Metropolitan Sanitary District Municipal and Industrial Wastewaters, BNWL-SA-2106, Battelle-Northwest, Richland, Washington. 1968.

H. H. Van Tuyz. ISOGEN, A Computer Code for Radioisotope Generation Calculations, HW-83785. Available from Clearinghouse for Federal Scientific and Technical Information, Springfield, Virginia, 1964. (A current version of ISOGEN, modified to include power reactor cross sections, is available from the Argonne Code Center, Argonne National Laboratories, 9700 So. Cass Avenue, Argonne, IZI., 60439) 
BNWL-1115

APPENDIX A

TABLES 
TABLE 1. Nuclear Power Forecast

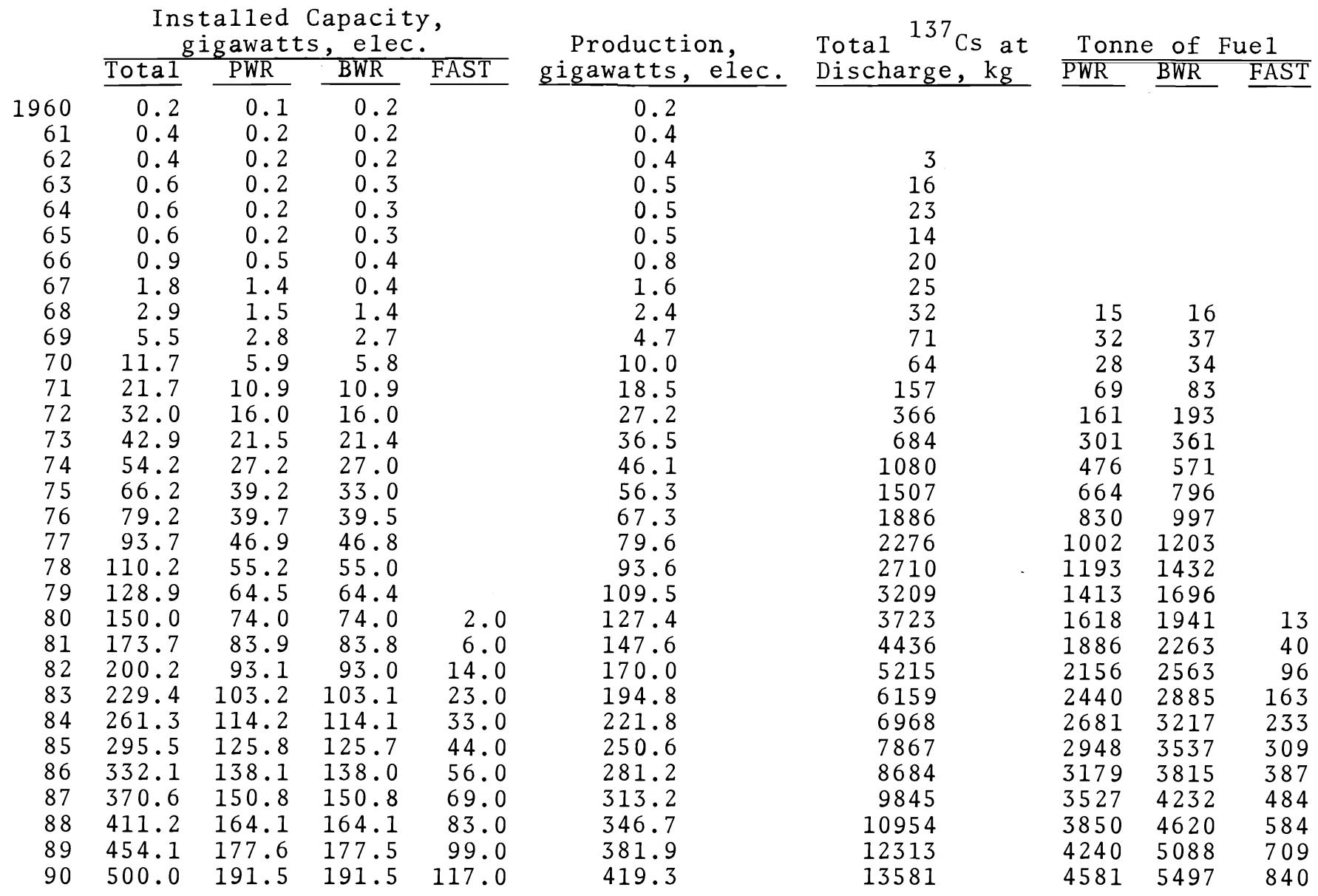


TABLE 2. Avaizability of (PWR and BWR) Mixed Fission Product Cylinders (Wastes Aged 2 Years from Reactor Discharge)

\begin{tabular}{cc} 
Year & Cylinders/Year \\
\cline { 2 - 2 } 1970 & 18 \\
1975 & 381 \\
1980 & 1511 \\
1985 & 3070 \\
1990 & 4877
\end{tabular}

TABLE 3. Amount of Wastes in PWR and BWR Fuels Aged Two years from Reactor Discharge

\begin{tabular}{|c|c|c|}
\hline & $\frac{\text { Grams Per }}{\text { PWR }}$ & $\frac{\text { Tonne of Fue } 1}{\frac{\text { BWR }}{1}}$ \\
\hline${ }^{155} \mathrm{Eu}$ & 1.837 & 1.483 \\
\hline${ }^{154} \mathrm{Eu}$ & 27.80 & 21.26 \\
\hline${ }^{147} \mathrm{Eu}$ & 83.19 & 71.23 \\
\hline${ }^{144} \mathrm{Eu}$ & 0.0022 & 0.0015 \\
\hline $144 \mathrm{Ce}$ & 52.09 & 34.58 \\
\hline${ }^{137} \mathrm{Cs}$ & 1087 & 901.4 \\
\hline${ }^{134} \mathrm{Cs}$ & 63.75 & 43.31 \\
\hline $125 \mathrm{~m}_{\mathrm{Cs}}$ & 0.057 & 0.046 \\
\hline $125_{\mathrm{Sb}}$ & 4.362 & 3.494 \\
\hline $110 \mathrm{~m}_{\mathrm{Ag}}$ & 0.0072 & 0.0055 \\
\hline${ }^{106} \mathrm{Ru}$ & 30.37 & 23.49 \\
\hline${ }^{95} \mathrm{Nb}$ & 0.0284 & 0.0189 \\
\hline $95 \mathrm{Zr}$ & 0.0243 & 0.0162 \\
\hline${ }^{91}{ }_{Y}$ & 0.0059 & 0.0045 \\
\hline${ }^{90} \mathrm{Y}$ & 0.1272 & 0.0983 \\
\hline $9^{9} \mathrm{Sr}$ & 486.2 & 386.6 \\
\hline${ }^{89} \mathrm{Sr}$ & 0.0010 & 0.0007 \\
\hline
\end{tabular}


TABLE 4. Gamma Spectrum of PWR Mixed Fission Products

Basis: Waste Fission Products from 1 tonne PWR Fuel at 30,000 $\mathrm{MWd} /$ tonne and $32.5 \mathrm{MW} /$ tonne

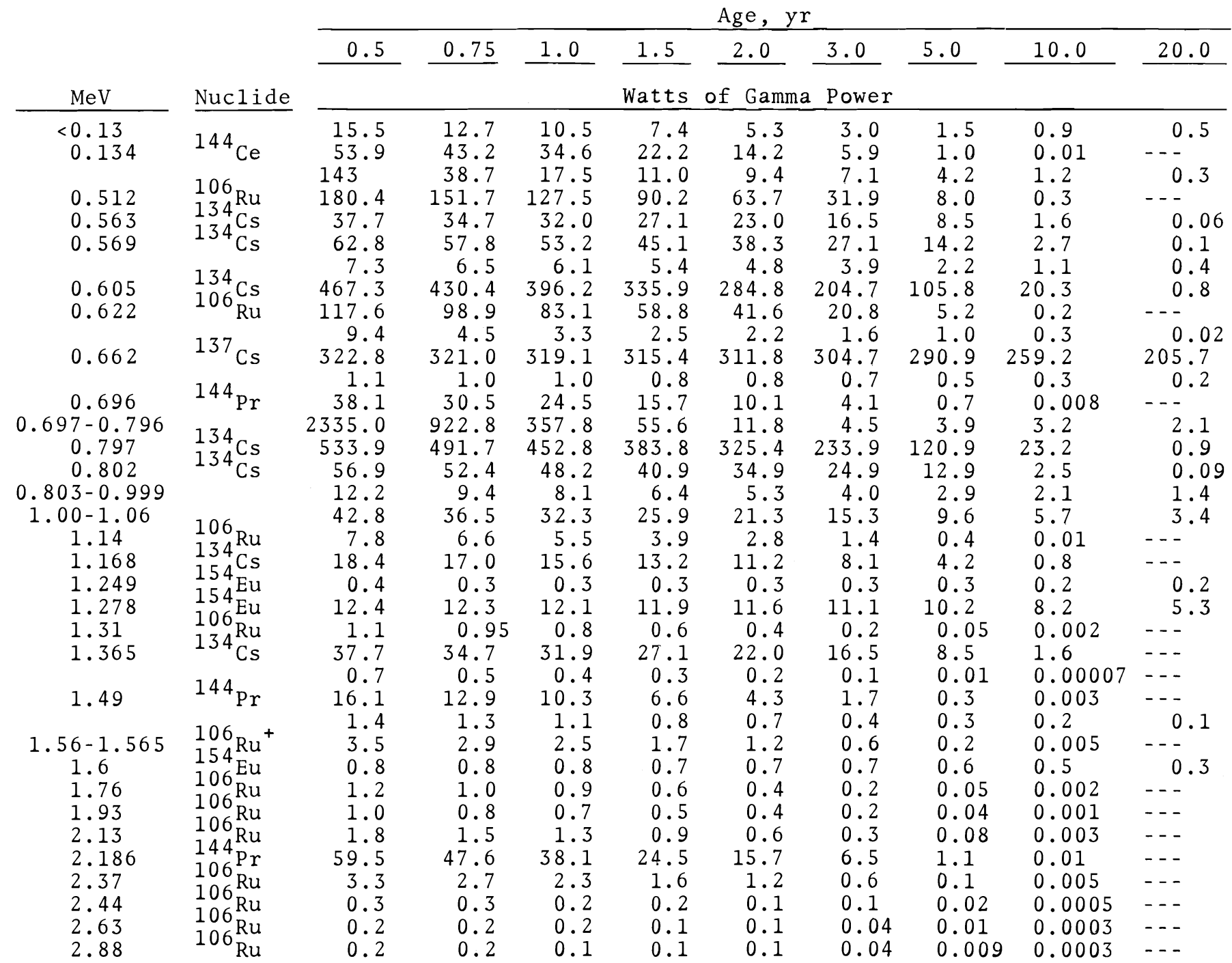


TABLE 5. Gamma Spectrum of BWR Mixed Fission Products

Basis: Waste Fission Products from 1 tonne BWR Fuel at 25,000 MWd/tonne and $20.3 \mathrm{MW} /$ tonne

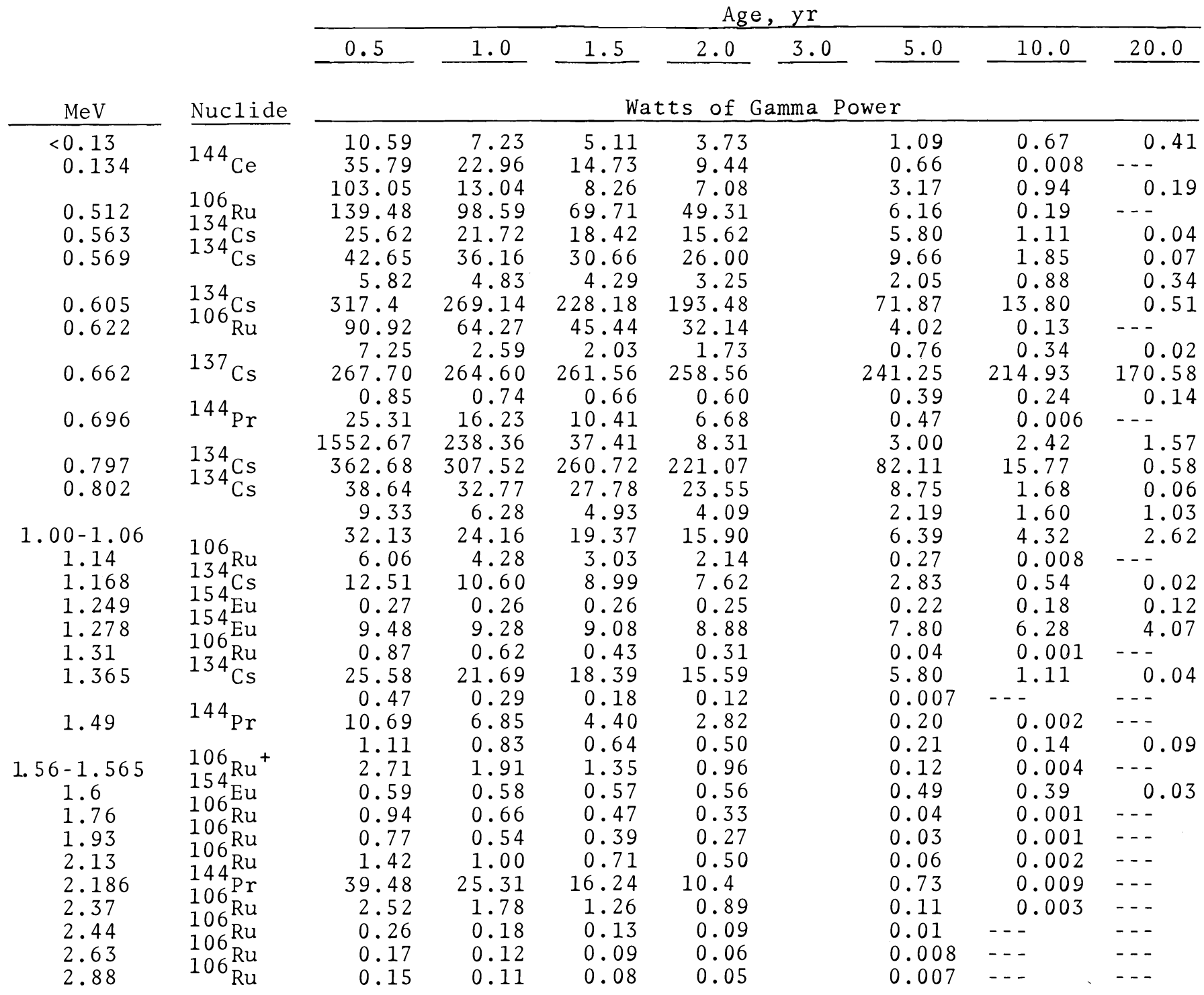


TABLE 6. Major Sources of Gamma Power (Watts)

Nuclide

$134 \mathrm{Cs}$

$137 \mathrm{Cs}$

$106 \mathrm{Ru}$

$154 \mathrm{Eu}$

$144 \mathrm{Pr}$

$144 \mathrm{Ce}$

$125 \mathrm{Sb}$

\begin{tabular}{|c|c|c|c|}
\hline \multicolumn{2}{|c|}{2 Years } & \multicolumn{2}{|c|}{10 Years } \\
\hline PWR & BWR & PWR & BWR \\
\hline $58.4 \%$ & $54.5 \%$ & $15.9 \%$ & $13.5 \%$ \\
\hline 24.3 & 27.7 & 77.0 & 79.7 \\
\hline 9.6 & 10.2 & & \\
\hline 2.4 & 2.5 & 6.4 & 6.1 \\
\hline 2.4 & 2.2 & & \\
\hline 1.4 & 1.3 & & \\
\hline 0.9 & 1.0 & & \\
\hline
\end{tabular}

TABLE 7. Effect of Self-Shielding and Cylinder wall shielding

\begin{tabular}{|c|c|c|c|c|c|}
\hline $\begin{array}{c}\text { Initial } \\
\gamma \mathrm{MeV} \\
\end{array}$ & $\begin{array}{l}\text { Fraction of } \\
\text { Initial Power } \\
\end{array}$ & $\begin{array}{c}\text { Primary } \\
\text { Attenuation } \\
\end{array}$ & Buildup & & \\
\hline $0 \quad-0.5$ & $(0.0225)$ & $(\sim 0.05)$ & $(\sim 4)$ & $=$ & $\sim 0.0045$ \\
\hline $0.5-0.8$ & $(0.90)$ & $(0.187)$ & $(2.8)$ & $=$ & 0.47124 \\
\hline $0.8-2.5$ & $(0.0775)$ & $(0.3)$ & $(2.5)$ & $=$ & 0.05813 \\
\hline
\end{tabular}


TABLE 8. Power Level (Watts) of PWR and BWR Cylinders

\begin{tabular}{|c|c|c|c|c|c|c|c|}
\hline \multirow{2}{*}{\multicolumn{2}{|c|}{$\begin{array}{l}\text { Age, Years } \\
\text { Since Reactor } \\
\text { Discharge }\end{array}$}} & \multicolumn{3}{|c|}{ PWR } & \multicolumn{3}{|c|}{ BWR } \\
\hline & & Thermal & Gamma & Total & Thermal & Gamma & Total \\
\hline \multicolumn{2}{|c|}{0.5} & 17883 & 3675 & 21558 & 17631 & 3389 & 21020 \\
\hline \multicolumn{2}{|c|}{0.75} & 13452 & 2298 & 15750 & & & \\
\hline \multicolumn{2}{|c|}{1.0} & 10768 & 1696 & 12464 & 10661 & 1609 & 12276 \\
\hline \multicolumn{2}{|c|}{1.5} & 7526 & 1228 & 8754 & 7451 & 1183 & 8634 \\
\hline \multicolumn{2}{|c|}{2.0} & 5573 & 1020 & 6593 & 5531 & 989 & 6520 \\
\hline \multicolumn{2}{|c|}{3.0} & 3429 & 766 & 4195 & & & \\
\hline \multicolumn{2}{|c|}{5.0} & 1932 & 493 & 2425 & 2034 & 498 & 2531 \\
\hline \multicolumn{2}{|c|}{10.0} & 1302 & 267 & 1570 & 1441 & 286 & 1727 \\
\hline \multicolumn{2}{|c|}{20.0} & 1045 & 176 & 1221 & 1199 & 194 & 1393 \\
\hline \multicolumn{8}{|c|}{$\begin{array}{l}\text { Note: These data include the effect of self-shielding and } \\
\text { cylinder wall shielding, i.e. thermal watts are } \\
\text { a+B+47\% of } \gamma \text {; ratts are } 53 \% \text { of those emitted by } \\
\text { the mixed fission products. }\end{array}$} \\
\hline
\end{tabular}



TABLE 9. $\begin{aligned} & \text { Energy from one Cylinder of PWR Mixed Fission } \\ & \text { Products (MFP) }\end{aligned}$

\begin{tabular}{|c|c|c|c|c|c|}
\hline \multicolumn{2}{|c|}{$\begin{array}{lc}\text { Time } & \text { Period } \\
\text { From } & \text { To } \\
\end{array}$} & $\begin{array}{c}\alpha+\beta \text { Emitted } \\
\text { By MFP, } \\
\text { kW-hr } \\
\end{array}$ & $\begin{array}{c}\gamma \text { Emitted } \\
\text { By MFP, } \\
\mathrm{kW}-\mathrm{hr} \\
\end{array}$ & $\begin{array}{c}\text { Heat From } \\
\text { Cylinder, } \\
\text { Btu } \\
\end{array}$ & $\begin{array}{c}\gamma^{\prime} \mathrm{s} \text { From } \\
\text { Cylinder, } \\
\mathrm{kW}-\mathrm{hr}\end{array}$ \\
\hline $\begin{array}{l}0.5 \\
2.0 \\
3.0 \\
4 \\
5 \\
6 \\
7 \\
8 \\
9 \\
10 \\
11 \\
12 \\
13 \\
14 \\
15 \\
16 \\
17 \\
18 \\
19\end{array}$ & $\begin{array}{l}2.0 \\
3.0 \\
4.0 \\
5 \\
6 \\
7 \\
8 \\
9 \\
10 \\
11 \\
12 \\
13 \\
14 \\
15 \\
16 \\
17 \\
18 \\
19 \\
20\end{array}$ & $\begin{array}{r}100460 \\
28080 \\
17730 \\
12400 \\
9930 \\
8480 \\
7665 \\
7150 \\
6960 \\
6890 \\
6825 \\
6770 \\
6720 \\
6680 \\
6630 \\
6590 \\
6560 \\
6530 \\
6500\end{array}$ & $\begin{array}{r}40730 \\
14040 \\
11010 \\
8960 \\
7460 \\
6360 \\
5600 \\
5040 \\
6400 \\
4200 \\
3850 \\
3600 \\
3420 \\
3240 \\
3130 \\
3060 \\
3000 \\
2950 \\
2920\end{array}$ & $\begin{array}{r}408 \times 10^{6} \\
118 \times 10^{6} \\
78.2 \times 10^{6} \\
56.7 \times 10^{6} \\
45.9 \times 10^{6} \\
39.1 \times 10^{6} \\
35.1 \times 10^{6} \\
32.5 \times 10^{6} \\
31.1 \times 10^{6} \\
30.3 \times 10^{6} \\
29.5 \times 10^{6} \\
28.9 \times 10^{6} \\
28.4 \times 10^{6} \\
28.0 \times 10^{6} \\
27.6 \times 10^{6} \\
27.4 \times 10^{6} \\
27.2 \times 10^{6} \\
27.0 \times 10^{6} \\
26.9 \times 10^{6} \\
\end{array}$ & $\begin{array}{l}21590 \\
7440 \\
5835 \\
4750 \\
3950 \\
3370 \\
2970 \\
2670 \\
2440 \\
2225 \\
2040 \\
1910 \\
1810 \\
1720 \\
1660 \\
1620 \\
1590 \\
1560 \\
1550\end{array}$ \\
\hline Total & & & & $1126 \times 10^{6}$ & 72700 \\
\hline $\begin{array}{l}0.5 \\
2.0\end{array}$ & $\begin{array}{r}2.0 \\
20.0\end{array}$ & & & $\begin{array}{l}408 \times 10^{6} \\
718 \times 10^{6}\end{array}$ & $\begin{array}{l}21590 \\
51110\end{array}$ \\
\hline $\begin{array}{l}0.5 \\
3.0\end{array}$ & $\begin{array}{r}3.0 \\
20.0\end{array}$ & & & $\begin{array}{l}526 \times 10^{6} \\
600 \times 10^{6}\end{array}$ & $\begin{array}{l}29030 \\
43670\end{array}$ \\
\hline $\begin{array}{l}0.5 \\
5.0\end{array}$ & $\begin{array}{r}5.0 \\
20.0\end{array}$ & & & $\begin{array}{l}661 \times 10^{6} \\
465 \times 10^{6}\end{array}$ & $\begin{array}{l}39620 \\
33090\end{array}$ \\
\hline
\end{tabular}


TABLE 10. Cost of 70 Kizowatt Gamma Source

Source Type

Mixed Fission Product

Cesium-137

Cobalt -60
Basis

Shipping Costs Only

$5 \$ /$ curie delivered

$10 \$ /$ curie delivered

$25 \$ /$ curie delivered

$50 \$ /$ curie delivered
Initial +

Annua 1

$\$ 87,000$

$\$ 10,000 /$ year (1st 15 Years)

$\$ 20,000 /$ year (1ater)

$\$ 1,200,000+\$ 27,000 /$ year

$\$ 2,400,000+\$ 54,000 /$ year

$\$ 1,425,000+\$ 177,000 /$ year

$\$ 2,850,000+\$ 353,000 /$ year 
BNWL - 1115

APPENDIX B

FIGURES 


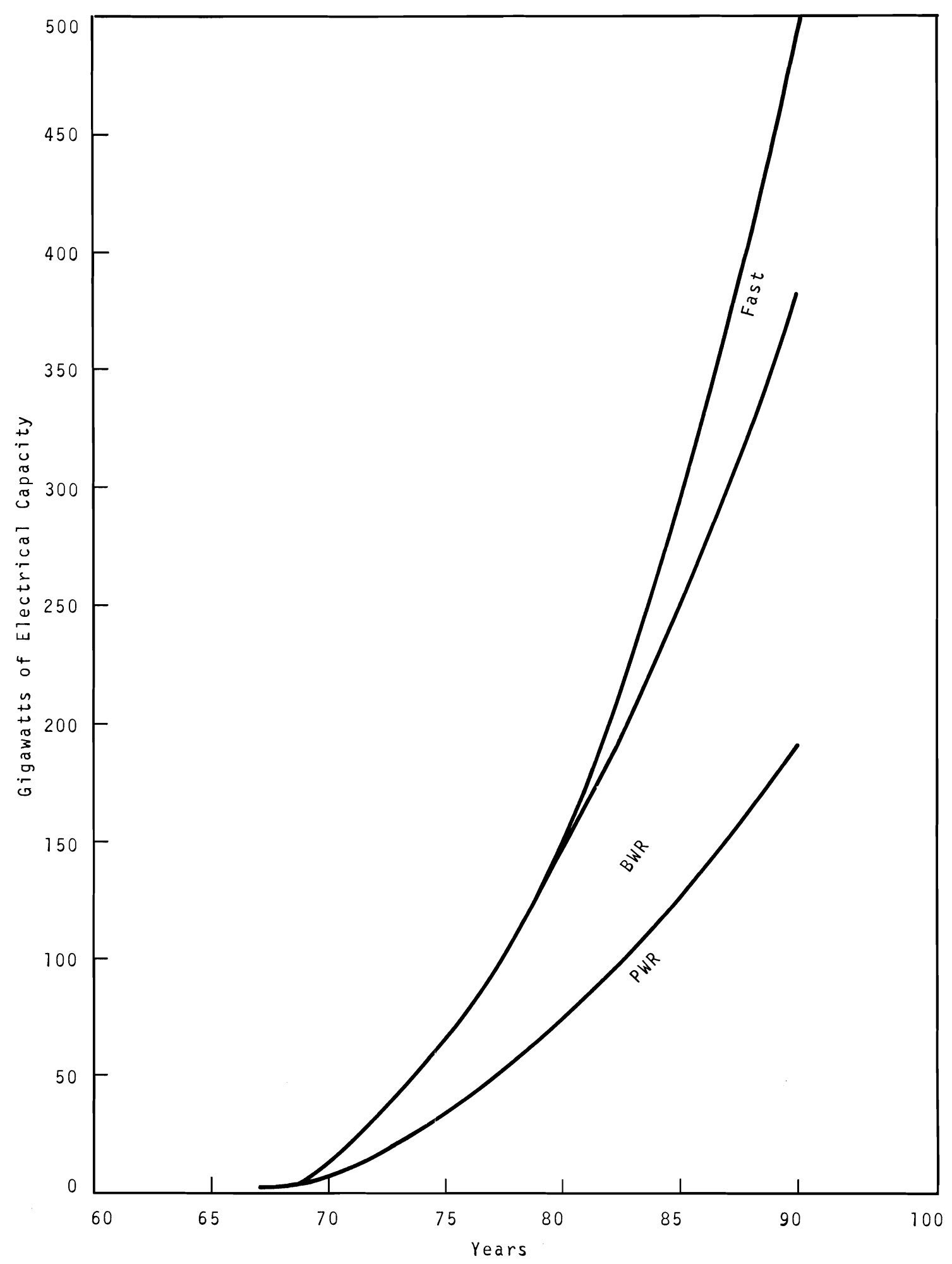

FIGURE 1. InstalZed Capacity - Nuclear EZectrical Generation 


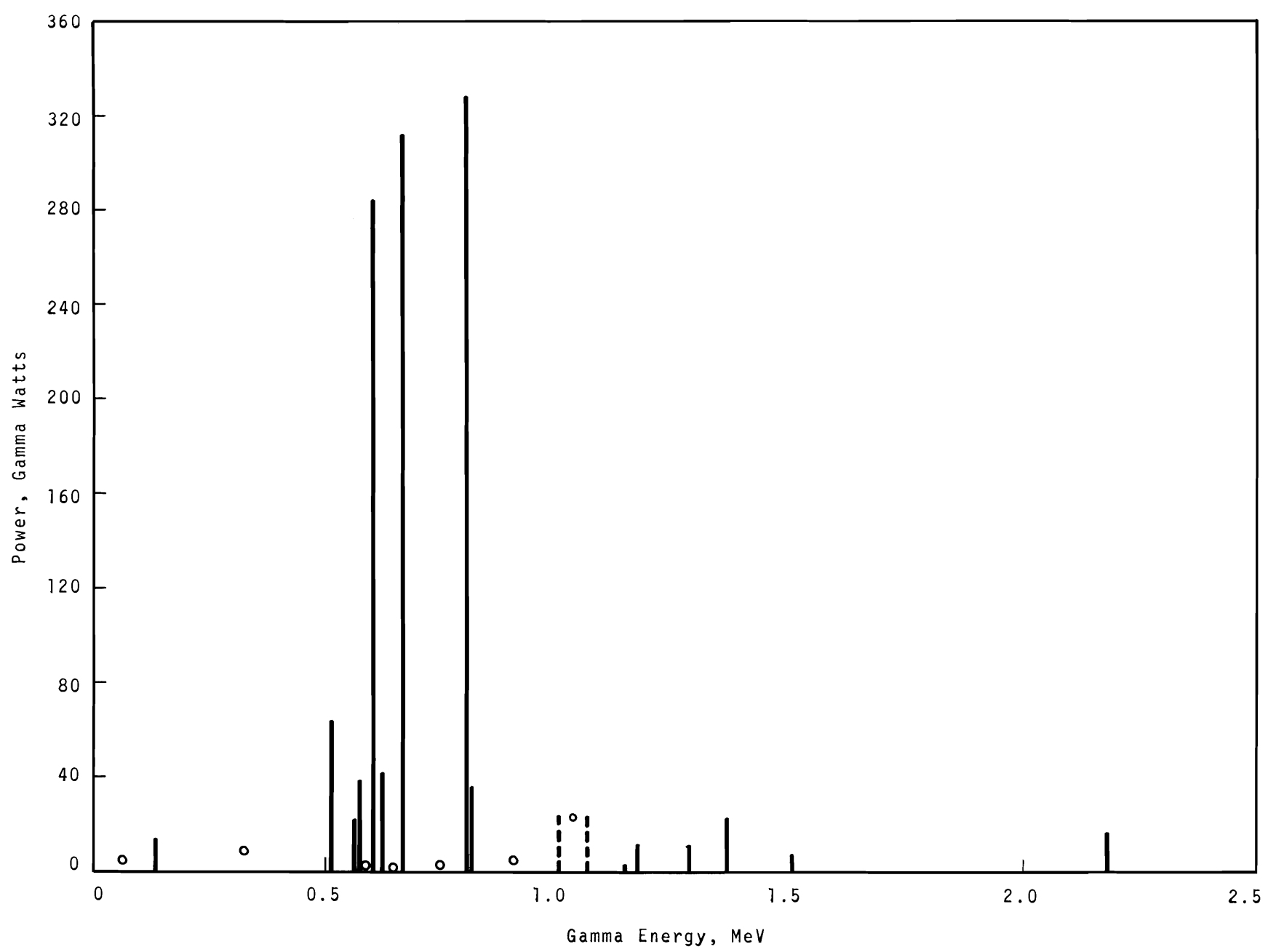

FIGURE 2. Gamma Spectra for PWR Mixed Fission Products (2 yr from reactor discharge) 


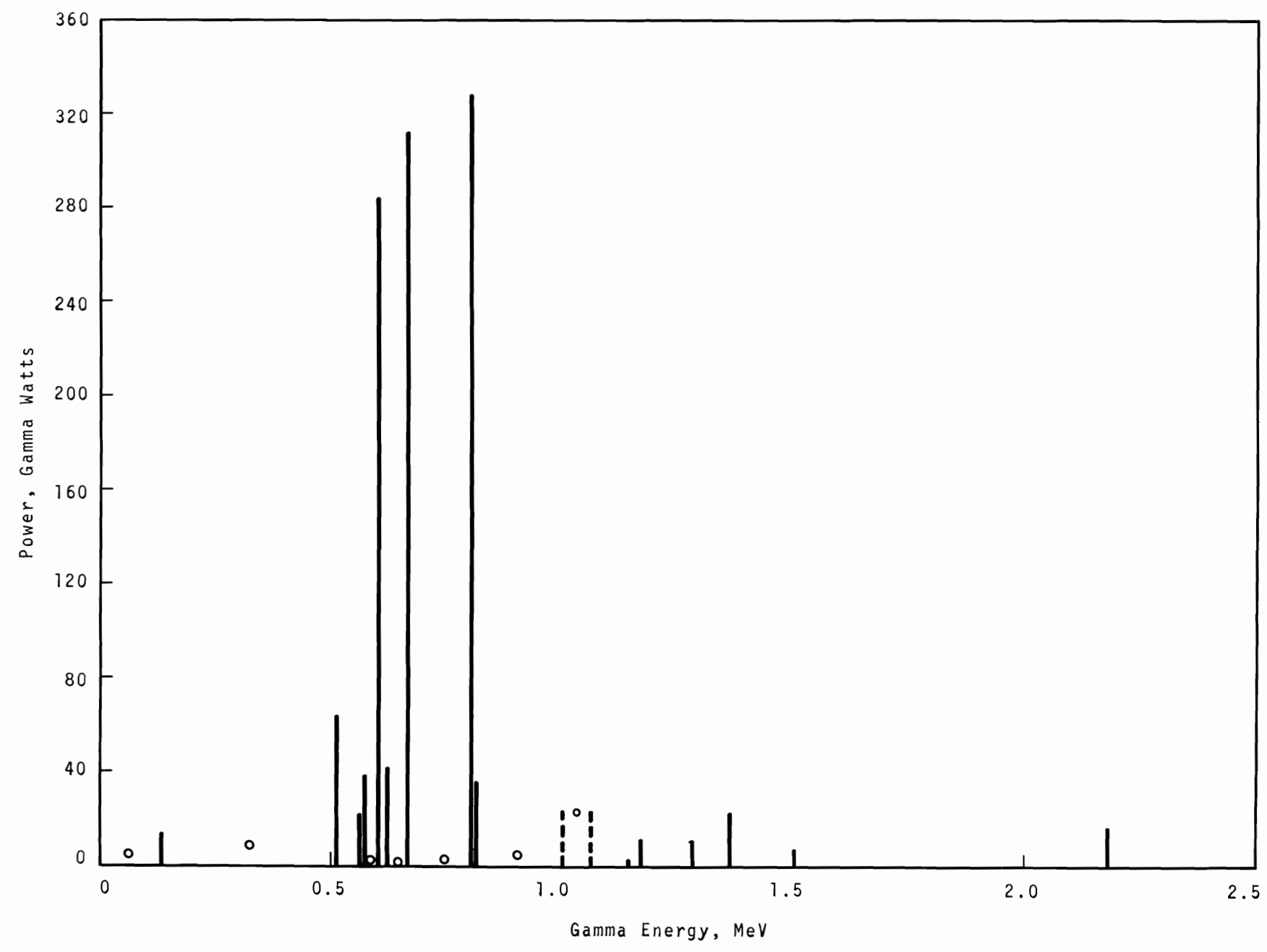

FIGURE 2. Gamma Spectra for PWR Mixed Fission Products (2 yr from reactor discharge) 


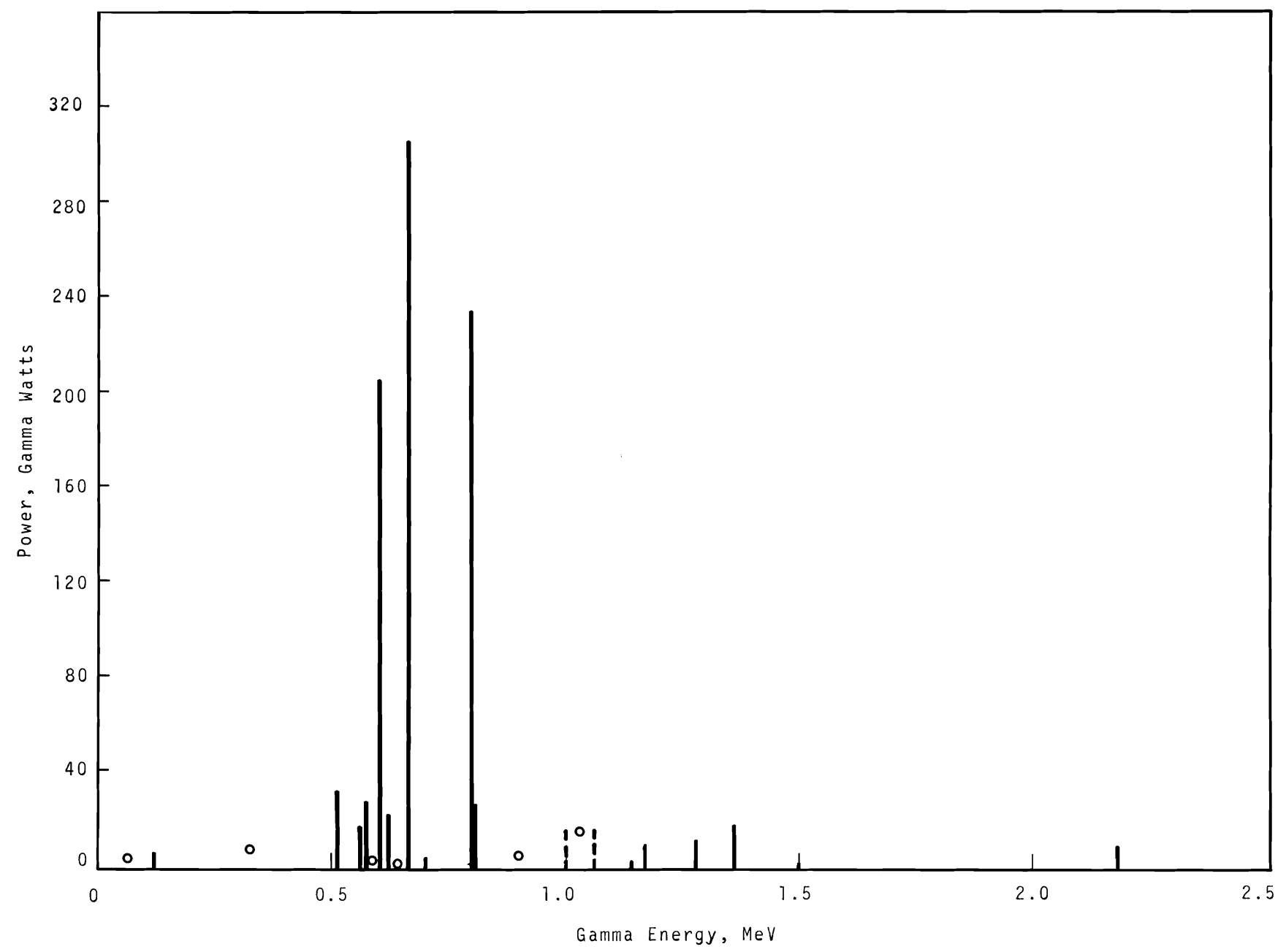

FIGURE 3. Gamma Spectra for PWR Mixed Fission Products (3 yr from reactor discharge) 


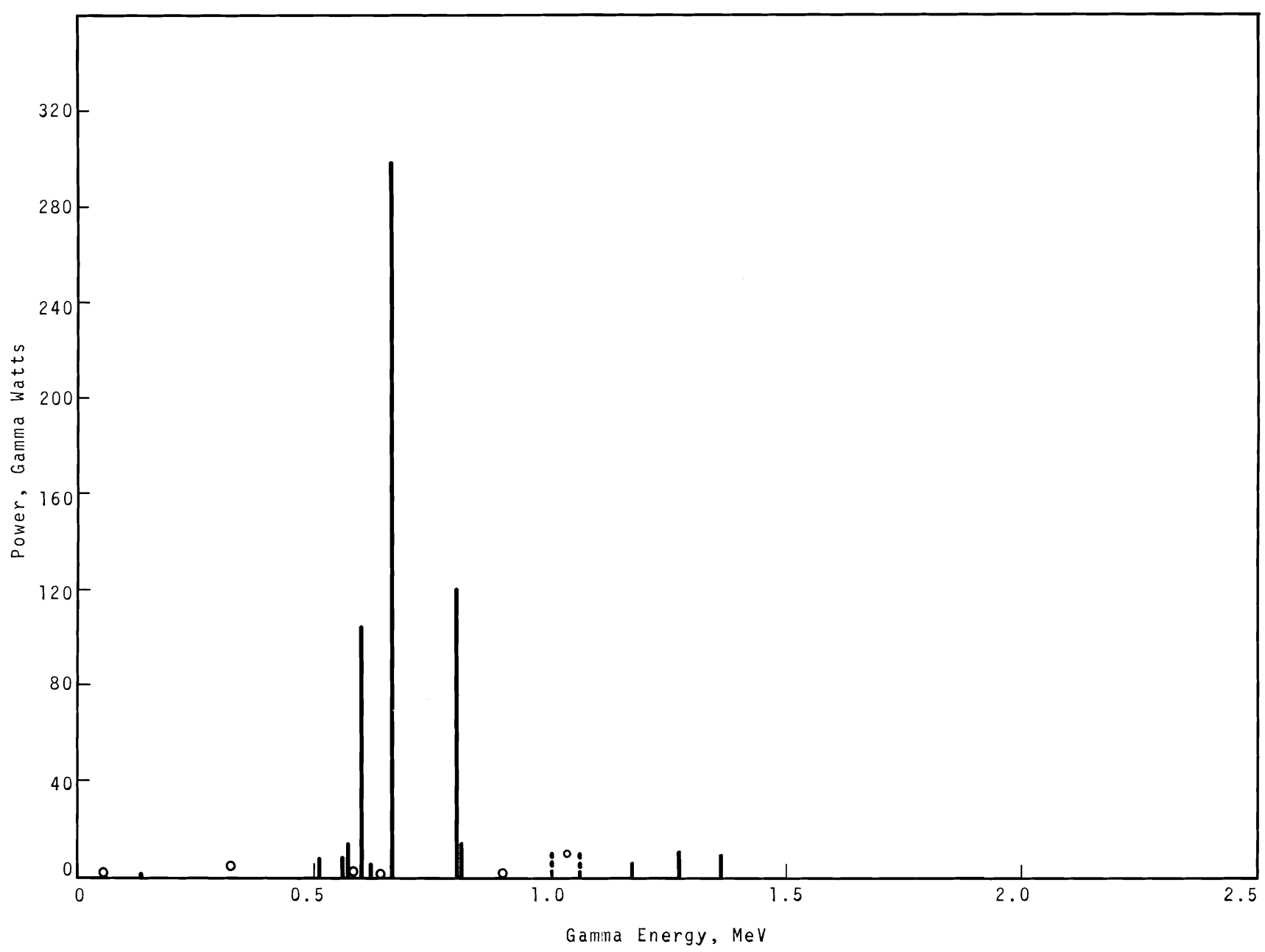

FIGURE 4. Gamma Spectra for PWR Mixed Fission Products (5 yr from reactor discharge) 


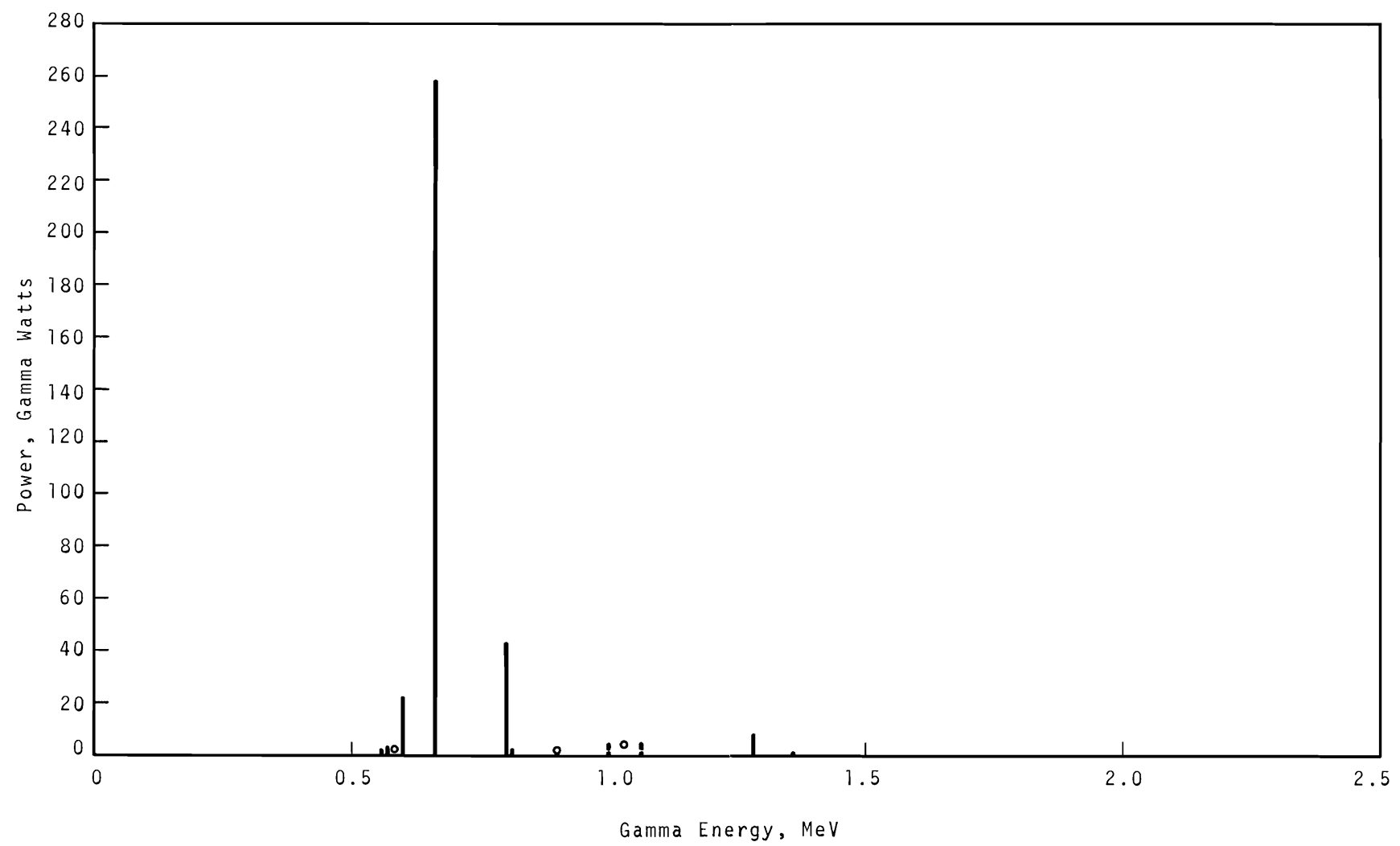

FIGURE 5. Gamma Spectra for PWR Mixed Fission Products (10 yr from reactor discharge) 


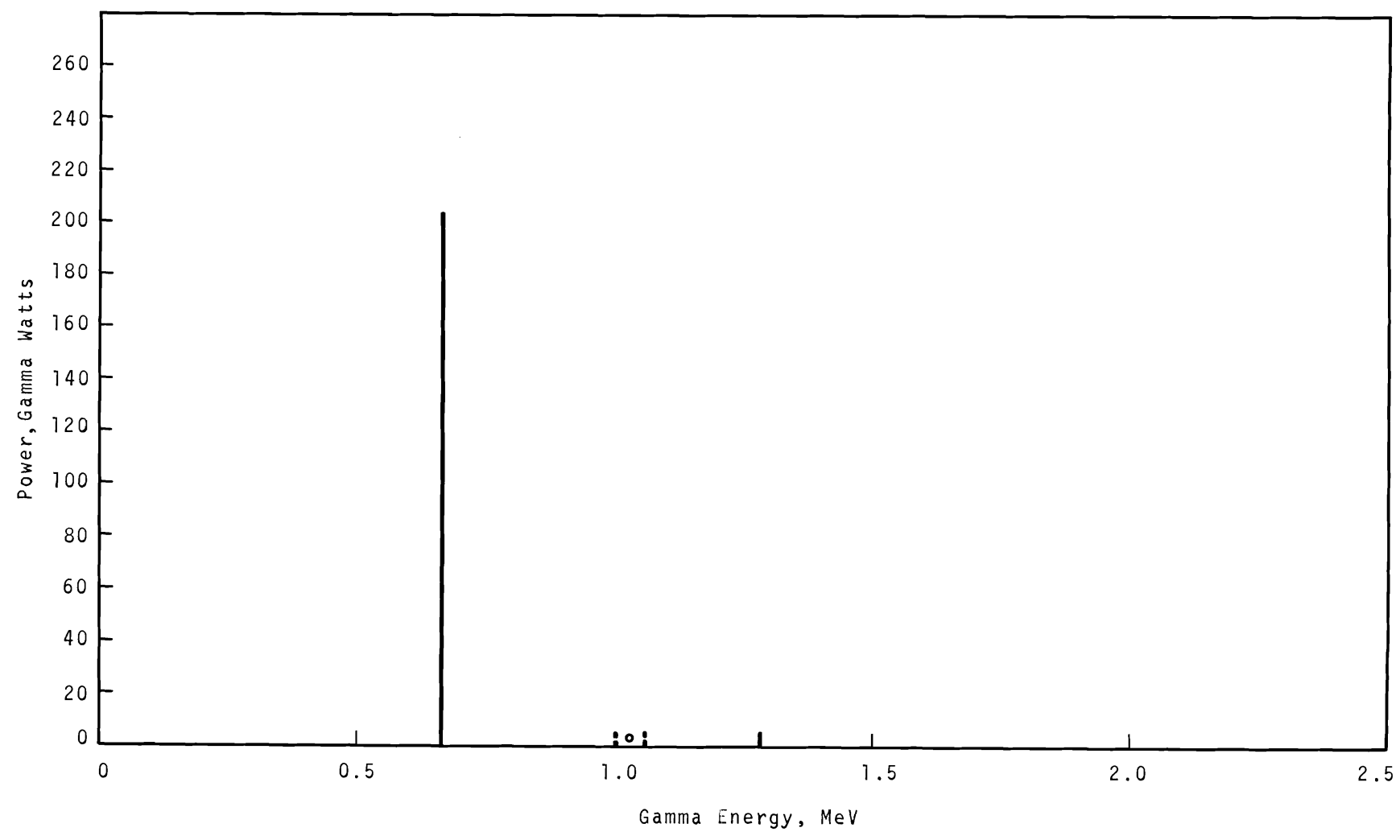

FIGURE 6. Gamma Spectra for PWR Mixed Fission Products (20 yr from reactor discharge) 


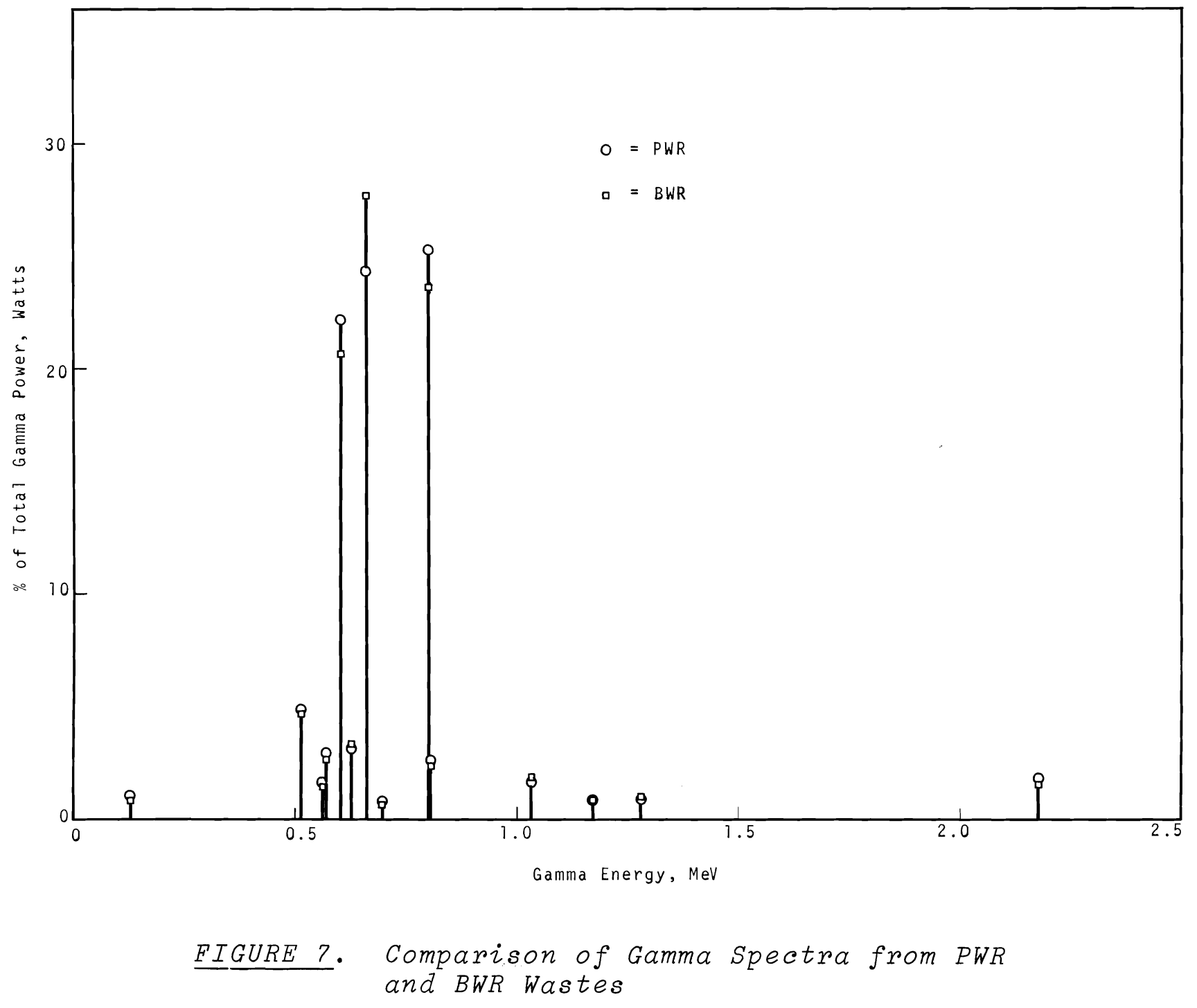




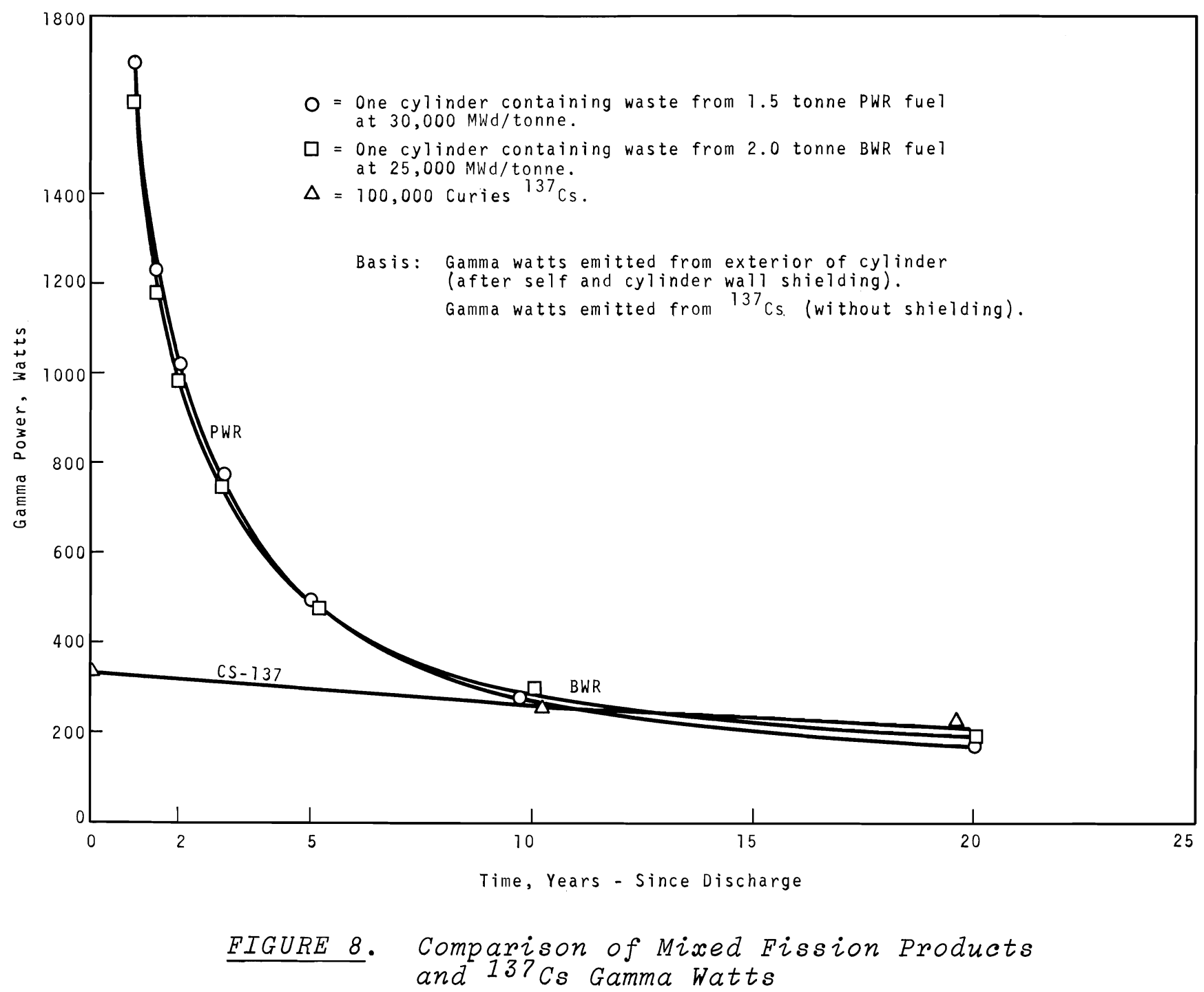




\section{DISTRIBUTION}

No. of

Copies

OFFSITE

AEC Chicago Patent Group

G. H. Lee

194 AEC Division of Technical Information Extension

ONSITE-HANFORD

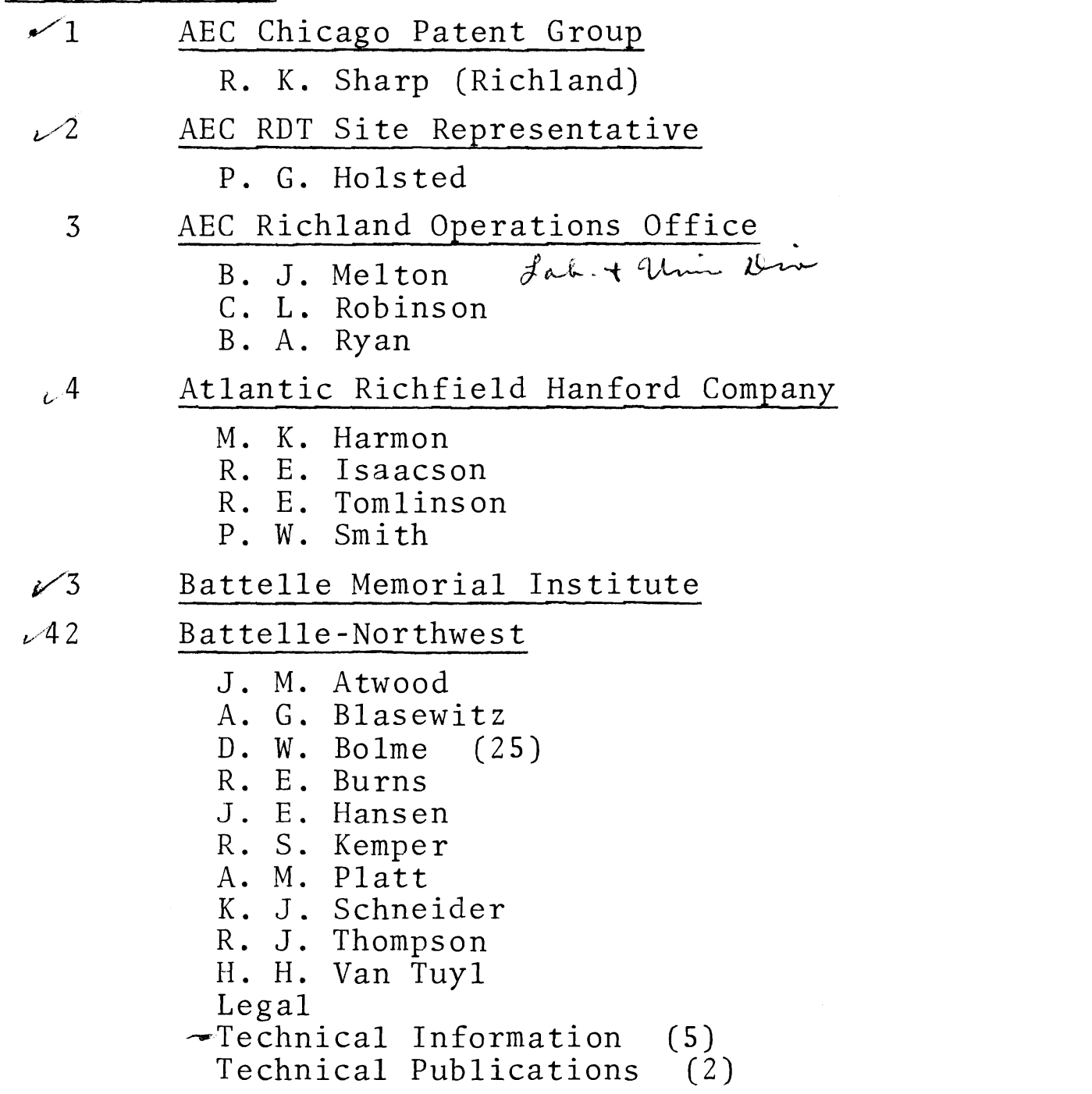

